\title{
New Compounds with Bioisosteric Replacement of Classic Choline Kinase Inhibitors Show Potent Antiplasmodial Activity
}

\author{
Francisco José Aguilar-Troyano ${ }^{1,+}{ }^{\mathbb{D}}$, Archimede Torretta ${ }^{2,+}{ }^{,}$, Gianluca Rubbini ${ }^{1}$, Alberto Fasiolo ${ }^{1}$, \\ Pilar María Luque-Navarro ${ }^{1}$, María Paz Carrasco-Jimenez ${ }^{3}{ }^{4}$, Guiomar Pérez-Moreno ${ }^{4}$, \\ Cristina Bosch-Navarrete ${ }^{4}$, Dolores González-Pacanowska ${ }^{4, *}$, Emilio Parisini 2,5,*(D) \\ and Luisa Carlota Lopez-Cara ${ }^{1, * \mathbb{D}}$
}

1 Department of Pharmaceutical and Organic Chemistry, Faculty of Pharmacy, Campus of Cartuja, 18071 Granada, Spain; francisco.aguilar_troyano@uni-wuppertal.de (F.J.A.-T.); gianluca.rubbini@unimi.it (G.R.); albertofasiolo@gmail.com (A.F.); pilarluque@ugr.es (P.M.L.-N.)

2 Center for Nano Science and Technology @PoliMi, Istituto Italiano di Tecnologia, Via Pascoli 70/3, 20133 Milano, Italy; archimede.torretta@iit.it

3 Department of Biochemistry and Molecular Biology I, Faculty of Sciences, 18071 Granada, Spain; mpazcj@ugr.es

check for updates

Citation: Aguilar-Troyano, F.J.; Torretta, A.; Rubbini, G.; Fasiolo, A.; Luque-Navarro, P.M.; CarrascoJimenez, M.P.; Pérez-Moreno, G.; Bosch-Navarrete, C.; GonzálezPacanowska, D.; Parisini, E.; et al. New Compounds with Bioisosteric Replacement of Classic Choline Kinase Inhibitors Show Potent Antiplasmodial Activity. Pharmaceutics 2021, 13, 1842. https:/ doi.org/10.3390/pharmaceutics 13111842

Academic Editor: Tihomir Tomašić

Received: 27 September 2021

Accepted: 20 October 2021

Published: 2 November 202

Publisher's Note: MDPI stays neutral with regard to jurisdictional claims in published maps and institutional affiliations.

Copyright: (c) 2021 by the authors. Licensee MDPI, Basel, Switzerland. This article is an open access article distributed under the terms and conditions of the Creative Commons Attribution (CC BY) license (https:// creativecommons.org/licenses/by/ $4.0 /)$.
4 Department of Biochemistry and Molecular Pharmacology, Institute of Parasitology and Biomedicine "López-Neyra", Spanish National Research Council, Parque Tecnológico de Ciencias de la Salud, Avenida del Conocimiento 17, 18016, Granada, Spain; guiomar@ipb11.ipb.csic.es (G.P.-M.); cristinabosch@ipb.csic.es (C.B.-N.)

5 Department of Organic Synthesis, Latvian Institute of Organic Synthesis, Aizkraukles 21, LV-1006 Riga, Latvia

* Correspondence: dgonzalez@ipb.csic.es (D.G.-P.); emilio.parisini@osi.lv (E.P.); lcarlotalopez@ugr.es (L.C.L.-C.); Tel.: +34-958-181-631 (D.G.-P.); +371-67014875 (E.P.); +34-958-243-849 (L.C.L.-C.)

$+\quad$ These authors contributed equally to this work.

Abstract: In the fight against Malaria, new strategies need to be developed to avoid resistance of the parasite to pharmaceutics and other prevention barriers. Recently, a Host Directed Therapy approach based on the suppression of the starting materials uptake from the host by the parasite has provided excellent results. In this article, we propose the synthesis of bioisosteric compounds that are capable of inhibiting Plasmodium falciparum Choline Kinase and therefore to reduce choline uptake, which is essential for the development of the parasite. Of the 41 bioisosteric compounds reported herein, none showed any influence of the linker on the antimalarial and enzyme inhibitory activity, whereas an effect of the type of cationic heads used could be observed. SARs determined that the thienopyrimidine substituted in 4 by a pyrrolidine is the best scaffold, independently of the chosen linker. The decrease in lipophilicity seems to improve the antimalarial activity but to cause an opposite effect on the inhibition of the enzyme. While potent compounds with similar good inhibitory values have been related to the proposed mechanism of action, some of them still show discrepancies and further studies are needed to determine their specific molecular target.

Keywords: antimalarial drug; choline kinase inhibition

\section{Introduction}

Malaria is a disease caused by Plasmodium, a parasite that involves cyclical infection between the female mosquito Anopheles and human erythrocytes. It is in the erythrocyte, where parasite division and sexual differentiation take place, thus allowing the diffusion of the pathogen in the bloodstream of the host and causing anaemia and organ failure in severe cases. 
The world regions at risk of the disease are sub-Saharan Africa, South-East Asia, Eastern Mediterranean, Western Pacific, and the Americas, a situation that affects nearly half of the world population and that continues to worsen with climate change.

In 2019, there were 229 million cases of malaria, the most fragile population being children under the age of five [1].

Owing to the problem of resistance development to antimalarials, insecticides and other prevention barriers, the scientific community has started to look for new strategies to block parasite progression and infection.

Vial et al. first proposed a strategy based on the suppression of the availability of the host's nutrients to the parasite [2]. They exploited the fact that once the parasite has infected the erythrocyte, there is a cycle of asexual division in which each member of the new progeny needs to be packed in a lipidic membrane. As the erythrocyte is a cell with no nucleus, it is the enzymatic machinery of the parasite that converts the host starting materials into the necessary phospholipids.

For this reason, the uptake inhibition of phospholipid precursors such as choline or ethanolamine can become a successful host-directed therapy (HDT) [2]. Other studies have focused on the inhibition of transporters necessary for the salvage of purine bases [3] and glucose [4], as the parasite is unable to carry out their de novo production.

Among the strategies based on differences between the host and the parasite metabolism, recent studies have shown that the reduction of the accessibility to phospholipids makes the parasite reproduce in a sexual rather than in an asexual way [5]. This reduces malaria mortality because of the lower erythrocytic infection by merozoites. Sexual differentiation results in the formation of gametocytes that remain in the bloodstream and disappear from the circulation if not taken up by a mosquito.

We have previously studied the enzymatic inhibition of Plasmodium falciparum Choline Kinase (PfCK), a monomeric protein whose crystallographic structure has been recently elucidated in complex with $\mathrm{Mg}^{2+}$ atoms and ATP [6]. In the structure, the catalytic pocket is very similar to its human CK equivalent, showing conserved hydrophobic and negatively charged residues where the positive charge of choline is stabilized.

Moreover, we have previously reported that biscationic inhibitors could show different mechanisms of action depending on their structure. For instance, biscationic (Figure 1) compounds with an aliphatic linker (BR23, BR25) can inhibit the ethanolamine kinase activity of $P f C K$ while other compounds (BR31, BR33, 10a-1) inhibit the choline kinase activity of the enzyme [7-9].

Some monocationic compounds have also been evaluated for their antitumor and antimalarial activity $[8,10-13]$. Recently, it was described that the different conformation adopted by the enzyme depending on whether the substrate is choline or ethanolamine could determine the different mode of binding adopted by the compounds in the CK pocket [7].

Two interesting reviews by Vial et al. [14,15] describe the acquisition of glycerophospholipids in Plasmodium, showing how the Kennedy pathway involves different mechanisms for the formation of phosphocholine (PC) and phosphoethanolamine (PE), the main membrane phospholipids, and how this pathway has autoregulatory mechanisms. In 2020, this review was updated by Mulaw [16] with new and interesting targets.

Clearly, exciting data validate $P f C K$ as a drug target in malaria disease. Plasmodium species parasites need to grow and multiply fueled by precursors supplied by the host. Among these precursors of particular importance are choline and ethanolamine used by the parasite to synthesize its phospholipids, mainly PC, the major phospholipid in Plasmodium membranes like in the rest of eukaryotes. It has been demonstrated that the specific inhibition of $P f C K$ disrupts its Kennedy pathway, resulting in parasite death. For this purpose, many chemical compounds targeting this enzyme have been developed. 


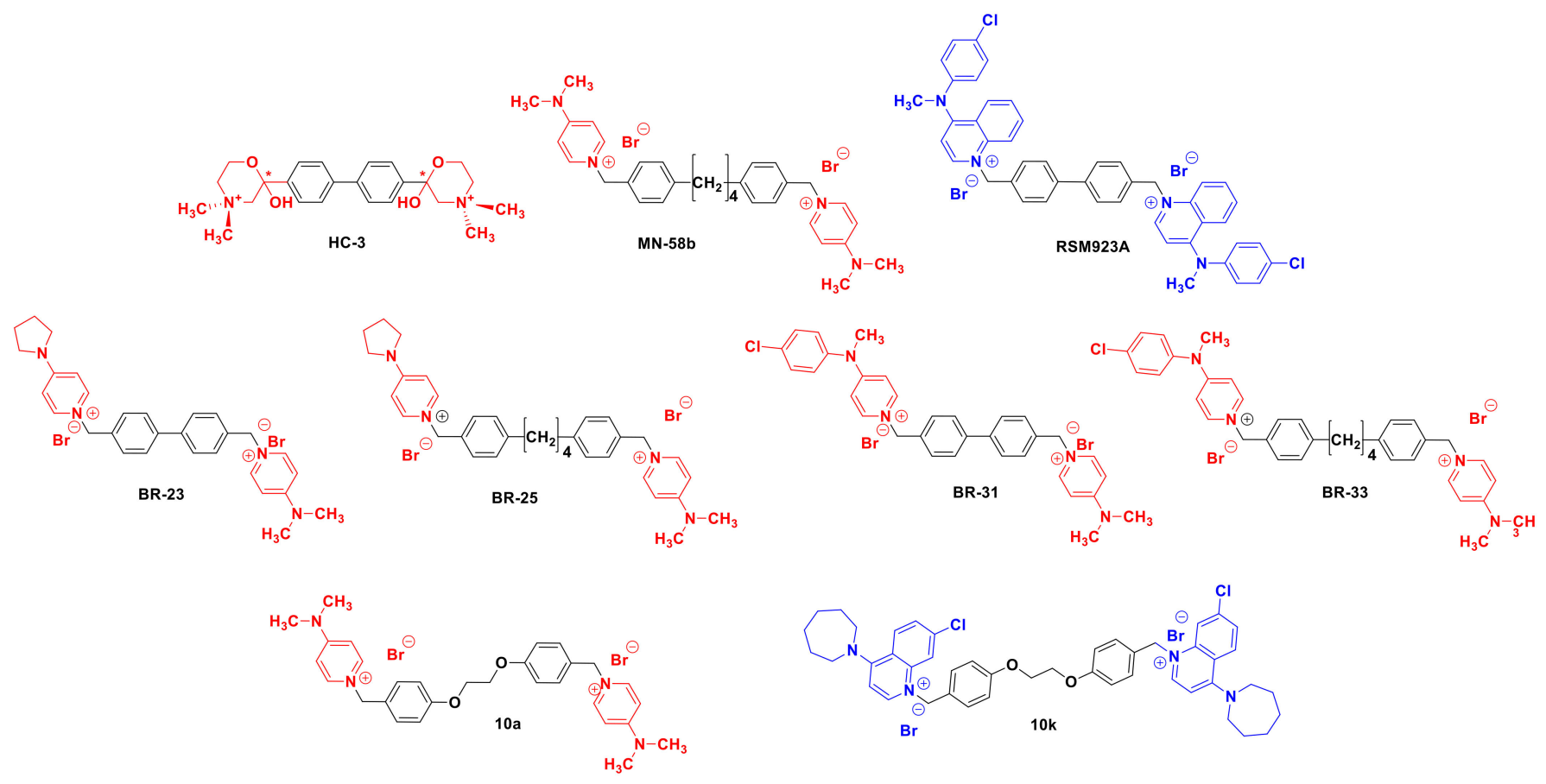

Figure 1. Reference compounds. In red color pyridinium derivatives and in blue color quinolinium derivatives.

Bioisosteric changes have also been shown to be very useful in reducing the toxicity or modifying the activity of many lead compounds, which also leads to pharmacokinetic alteration. Therefore, the bioisosterism strategy has been widely used to develop new therapeutic substances used as receptor antagonists or agonists, enzyme inhibitors and antimetabolites.

The substitution of quinoline by thienopyridine has been extensively studied in different pathologies related to kinase inhibition. Among them, a large number of thienopyrimidine derivatives have been published where their antitumor activity has been enhanced by inhibiting multiple enzymes as well as by modulating the activity of many receptors [3,17-24].

These observations, together with the low toxicity described for some of these previous compounds [3,17-24], have led us to evaluate all compounds described in this work as antimalarials and to study their possible mechanism of action as inhibitors of PfCK as the first approach in our study.

In the search for improving antimalarial activity, we present here the synthesis and biological evaluation of 41 compounds in which bioisosteric changes have been introduced on the cationic heads. While retaining the linkers used so far between the two heads, three types of cationic heads were chosen: thieno[3,2-b] pyridine, thieno [2,3-d] pyrimidine and thieno[3,2-d] pyrimidine (Figure 2 and Table 1). Those structures were selected in order to study the effect of introducing bioisosteric changes over the antimalarial activity and the enzymatic inhibition. In addition, these new derivatives were developed with the aim to determine whether the replacement of quinoline and pyridine as cationic heads of the classical compounds would enable the molecules to adopt the correct geometry for activity. Furthermore, the presence of the additional electron pair in the new $\mathrm{N}$ and $\mathrm{S}$ atoms would lead to an increase in the affinity for the target through the formation of new hydrogen bonds, together with an increase in bioavailability resulting from its higher solubility. 


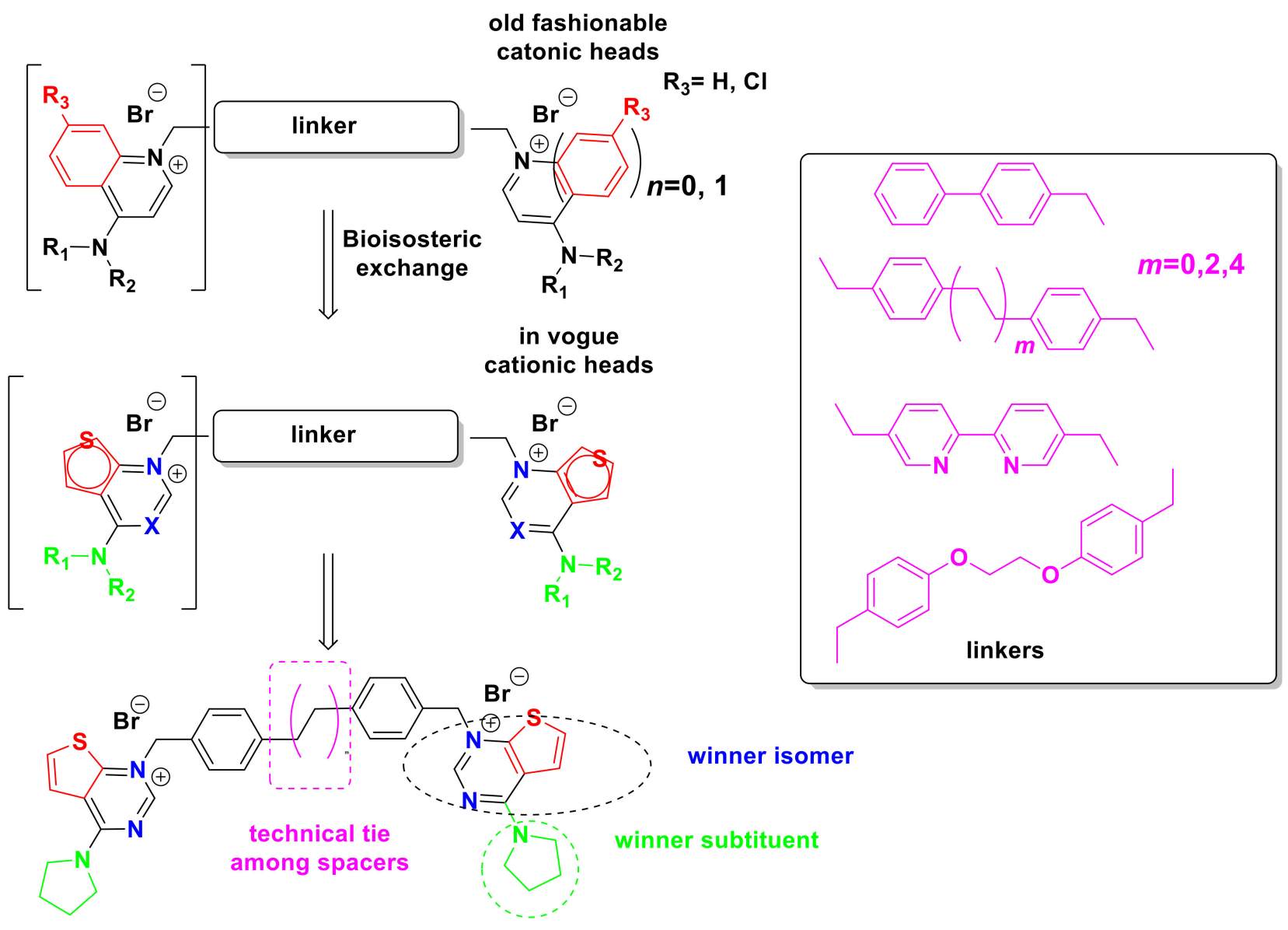

$X=C, N ; R_{1}=R_{2}=-C_{3} ; R_{1}=R_{2}=\left(-C_{2}\right)_{4} ; R_{1}=R_{2}=\left(-C_{2}-\right)_{5} ; R_{1}=R_{2}=\left(-C_{2}-\right)_{6}$;

$\mathrm{R}_{1}=-\mathrm{CH}_{3} ; \mathrm{R}_{2}=-\mathrm{C}_{6} \mathrm{H}_{5} ; \mathrm{R}_{1}=-\mathrm{CH}_{3} ; \mathrm{R}_{2}=-p-\mathrm{Cl}-\mathrm{C}_{6} \mathrm{H}_{4}$

Figure 2. General Structure of final compounds.

Table 1. Final Compounds synthetized and evaluated. The different bioisosteric cationic head are showed in blue, black and red respectively.

\begin{tabular}{cccc}
\hline \multicolumn{1}{c}{ Compounds } & Linker (a-f) & Bioisosteric Cationic Head & 4-Subtituent \\
\hline Fa-M2 & thieno[3,2-b]pyridin-1-ium & Pyrrolidinyl \\
Fa-M1 monocationic & & thieno[2,3-d]pyrimidin-1-ium \\
Fa-M3 & & thieno[3,2-d]pyrimidin-1-ium \\
\hline
\end{tabular}


Table 1. Cont.

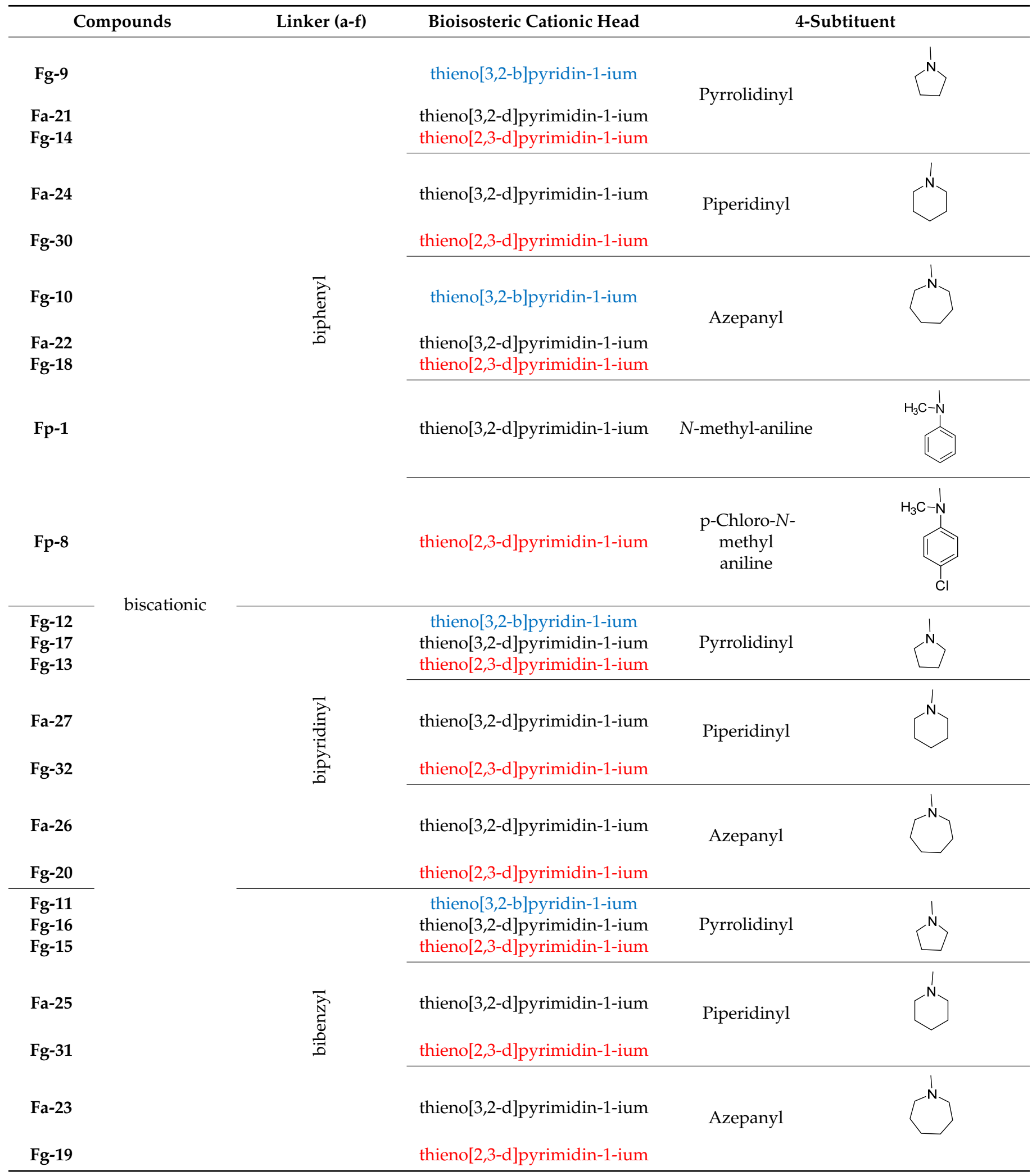


Table 1. Cont.

\begin{tabular}{|c|c|c|c|}
\hline Compounds & Linker (a-f) & Bioisosteric Cationic Head & 4-Subtituent \\
\hline $\begin{array}{l}\text { Ff-1 } \\
\text { Ff-7 } \\
\text { Ff-3 }\end{array}$ & & $\begin{array}{l}\text { thieno[3,2-b]pyridin-1-ium } \\
\text { thieno[3,2-d]pyrimidin-1-ium } \\
\text { thieno[2,3-d]pyrimidin-1-ium }\end{array}$ & Pyrrolidinyl \\
\hline $\begin{array}{l}\text { Fa-33 } \\
\text { Ff-6 }\end{array}$ & 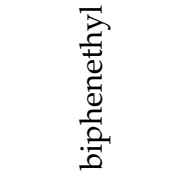 & $\begin{array}{l}\text { thieno[3,2-d]pyrimidin-1-ium } \\
\text { thieno[2,3-d]pyrimidin-1-ium }\end{array}$ & Piperidinyl \\
\hline Fa-29 & & thieno[3,2-d]pyrimidin-1-ium & Azepanyl \\
\hline Ff-35 & & thieno[2,3-d]pyrimidin-1-ium & \\
\hline $\begin{array}{l}\text { Ff-2 } \\
\text { Ff-8 } \\
\text { Ff-4 }\end{array}$ & & $\begin{array}{l}\text { thieno[3,2-b]pyridin-1-ium } \\
\text { thieno[3,2-d]pyrimidin-1-ium } \\
\text { thieno[2,3-d]pyrimidin-1-ium }\end{array}$ & Pyrrolidinyl \\
\hline Ff-5 & 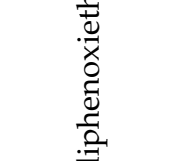 & $\begin{array}{l}\text { thieno[3,2-d]pyrimidin-1-ium } \\
\text { thieno[2,3-d]pyrimidin-1-ium }\end{array}$ & Piperidinyl \\
\hline Ff-34 & & thieno[3,2-d]pyrimidin-1-ium & Azepanyl \\
\hline Ff-36 & & thieno[2,3-d]pyrimidin-1-ium & \\
\hline
\end{tabular}

\section{Materials and Methods}

\subsection{Chemistry}

Melting points were taken in open capillaries on a Stuart Scientific SMP3 electrothermal melting-point apparatus and were uncorrected. Analytical thin-layer chromatography (TLC) was performed using Merck Kieselgel 60 F254 aluminium plates and visualized by UV light or iodine. All evaporation occurred in vacuo with a Büchi rotary evaporator (Büchi, Barcelona, Spain) and the pressure was controlled by a Vacuubrand CVCII apparatus (Vacuubrand, Wertheim, Germany). For flash chromatography, Merck silica gel 60 with a particle size of 0.040-0.063 mm (230-400 mesh ASTM) was used (Merck KGaA, Darmstadt, Germany). For NMR spectra were used: $500 \mathrm{MHz}{ }^{1} \mathrm{H}$ and $126 \mathrm{MHz}{ }^{13} \mathrm{C}$ NMR Varian Direct Drive; a $400 \mathrm{MHz}{ }^{1} \mathrm{H}$ and $101 \mathrm{MHz}{ }^{13} \mathrm{C}$ NMR Varian Direct Drive spectrometers at room temperature (Varian Medical Systems, Palo Alto, CA, USA). Chemical shifts ( $\delta$ ) are quoted in parts per million (ppm) and are referenced to the residual solvent peak. Spin multiplicities are given as s (singlet), bs (broad singlet), d (doublet), $\mathrm{t}$ (triplet), ddd (doublet doublet doublet), dd (doublet doublet), dt (doublet triplet), q (quadruplet) and $\mathrm{m}$ (multiplet). High-resolution NanoAssisted Laser Desorption/Ionization (NALDI-TOF) or Electrospray Ionization (ESI-TOF) mass spectra were carried out on a Bruker Autoflex or a Waters LCT Premier Mass (Agilent Scientific Instruments, Santa Clara, CA, USA). Organic solutions were dried over anhydrous $\mathrm{Na}_{2} \mathrm{SO}_{4}$. Solvents and reagents that are commercially available were purchased from Aldrich (Sigma-Aldrich, Burlington, MA, USA) or Alfa Aesar (Johnson Matthey Company London, England, UK) and were used without further purification unless otherwise noted. 


\subsection{Cloning, Protein Expression and Purification of PfCK}

A truncated form of PfCK $(\Delta 79-440)$ featuring an $N$-terminal $6 \times$ His-tag was purchased from Genescript (Piscataway, NJ, USA), cloned into a pET-28a vector and transformed into Escherichia coli BL21 (DE3) Star cells (Invitrogen, Carlsbad, CA, USA). The transformed bacteria were cultured in Luria-Bertani (LB) medium at $37^{\circ} \mathrm{C}$ until $\mathrm{OD}_{600}=0.6$ and the expression was induced with $1 \mathrm{mM}$ isopropyl $\beta$-D-1-thiogalactopyranoside (IPTG). The cell culture was grown overnight at $20^{\circ} \mathrm{C}$ and $180 \mathrm{rpm}$. Cells were pelleted by centrifugation at 10,000 rpm, resuspended in $50 \mathrm{mM}$ Tris/ $\mathrm{HCl} \mathrm{pH} \mathrm{7.5,500} \mathrm{mM} \mathrm{NaCl,} 0.2 \mathrm{mM}$ phenylmethylsulphonyl fluoride (PMSF, Sigma Aldrich, St. Luis, MO, USA), DNase (Sigma Aldrich, St. Luis, MO, USA), $0.5 \mathrm{mM} \beta$-mercaptoethanol (Sigma Aldrich, St. Luis, MO, USA) and sonicated. Separation of the soluble from the insoluble fraction was obtained by centrifugation at $15,000 \mathrm{rpm}$ and $4{ }^{\circ} \mathrm{C}$. The target enzyme was purified by a two-step purification protocol. In the first step, the cell lysate was incubated for 45 min with $\mathrm{Ni}$ NTA resin (Qiagen, Venlo, The Netherlands) in a gravity column. Then, the column was washed with 40 column volumes (CV) of $50 \mathrm{mM}$ Tris/ $\mathrm{HCl} \mathrm{pH} \mathrm{7.5,300} \mathrm{mM} \mathrm{NaCl}, 10 \mathrm{mM}$ imidazole and $1 \mathrm{CV}$ of $50 \mathrm{mM}$ Tris $/ \mathrm{HCl} \mathrm{pH} 7.5,300 \mathrm{mM} \mathrm{NaCl}, 40 \mathrm{mM}$ imidazole. Finally, the His-tagged enzyme was eluted from the column using a $50 \mathrm{mM}$ Tris/ $\mathrm{HCl} \mathrm{pH} 7.5$, $300 \mathrm{mM} \mathrm{NaCl}, 400 \mathrm{mM}$ imidazole buffer. A subsequent size-exclusion chromatography step was implemented to further polish the sample using a HiPrep 26/60 Sephacryl $100 \mathrm{HR}$ column (GE Healthcare, Little Chalfont, Buckinghamshire, UK) previously equilibrated with $20 \mathrm{mM}$ Tris/ $\mathrm{HCl} \mathrm{pH} \mathrm{7.5,} 150 \mathrm{mM} \mathrm{NaCl}$ buffer. This second purification step afforded a pure protein sample. The protein production yield was estimated to be nearly $2.5 \mathrm{mg}$ of recombinant enzyme per liter of bacterial culture [7].

\subsection{Enzymatic Assay for the Calculation of the $I C_{50}$ s of the Selected Compounds}

A spectrophotometric 96-well plate assay for $P f C K$ activity was established based on an assay previously described [7]. The reaction mix was composed as follows: $100 \mathrm{mM}$ Tris/ $\mathrm{HCl} \mathrm{pH} \mathrm{7.5,} 100 \mathrm{mM} \mathrm{KCl}, 10 \mathrm{mM} \mathrm{MgCl} 2,0.5 \mathrm{mM}$ phosphoenolpyruvate, $0.25 \mathrm{mM}$ $\mathrm{NADH}, 4 \mathrm{U}$ of pyruvate kinase, $5 \mathrm{U}$ lactate dehydrogenase, $2 \mathrm{mM} \mathrm{ATP}, 4 \mathrm{mM}$ choline chloride and different concentrations of the selected compounds. All the necessary compounds for the assay were purchased from Sigma Aldrich (St. Luis, MO, USA) and the final assay volume was $200 \mu \mathrm{L}$. The enzymatic reaction was initiated by the addition of the enzyme at less than $10 \mathrm{nM}$ concentration and the reaction rates were measured by monitoring the decrease in the absorbance at $340 \mathrm{~nm}$ for $20 \mathrm{~min}$ at room temperature using a Spark10M instrument (Tecan). Finally, the $\mathrm{IC}_{50}$ values for each compound were determined by plotting the enzyme fractional activity (f.a.) against the logarithm of compound concentration $(\log [\mathrm{I}])$. Curve-fitting was performed with a dose-response curve from Origin (OriginLab Corporation, Northampton, MA, USA), using the following equation:

$$
\text { f.a. }=\frac{1}{1+10^{\log \left(I C_{50}\right)-\log [I]}}
$$

All data points were collected in triplicate and the final dose-response curves were plotted with MATLAB (R2018a (9.4.0.813654), 2018, MathWorks, Natick, MA, USA). See curves in Figure S1 in Supplementary Materials.

\subsection{Antimalarial Activity}

Parasites of the P. falciparum strain 3D7 were grown in fresh group 0 positive human erythrocytes, obtained from the Centro Regional de Transfusion Sanguínea-SAS (Granada, Spain) and suspended at 5\% haematocrit in RPMI 1640 containing 2\% human serum, $0.2 \% \mathrm{NaHCO}_{3}, 0.5 \%$ Albumax II, $150 \mu \mathrm{M}$ hypoxanthine, and $12.5 \mathrm{mg} / \mathrm{mL}$ gentamicin. Flasks were incubated at $37{ }^{\circ} \mathrm{C}$, under $5 \% \mathrm{CO}_{2}$ and $95 \%$ air mixture. The stock culture was synchronized with $5 \%$ sorbitol, and then approximately $96 \mathrm{~h}$ later, the parasites were determined to be mostly late ring stages and early trophozoites. The stock culture was then diluted with complete medium and non-parasitized erythrocytes to yield a haematocrit 
of $2 \%$ and parasitemia of $0.25 \%$. Stock solutions of the test drugs were prepared at an initial concentration of $200 \mathrm{mM}$ in DMSO, serially diluted and dispensed into triplicate in 96-well plates to yield final concentrations ranging from 0.0039 to $2 \mu \mathrm{M}$. The final well volume was $200 \mu \mathrm{L}$ with a final concentration of DMSO 0.001\%. Each plate also included positive growth controls, where only medium were added, and negative growth controls with $100 \mathrm{nM}$ of chloroquine. $\left(\mathrm{IC}_{50}=0.015 \mu \mathrm{M}\right)$. A multidrop dispenser was used to add $50 \mu \mathrm{L}$ of synchronized parasite culture per well. After $72 \mathrm{~h}$ of growth in presence of test compounds, the plates were stored frozen at $-20{ }^{\circ} \mathrm{C}$ for at least $24 \mathrm{~h}$. Next, they were thawed at room temperature. Parasite growth inhibition assays and $\mathrm{IC}_{50}$ determinations were carried out following the $P$. falciparum lactate dehydrogenase assay [9] where parasite viability is quantified by measuring LDH activity upon APAD+ addition, a cofactor that is specific to the Plasmodium enzyme. To evaluate LDH activity, $140 \mu \mathrm{L}$ of freshly made reaction mix, containing $143 \mathrm{mM}$ sodium L-lactate, $143 \mu \mathrm{M}$ APAD, $178.75 \mu \mathrm{M}$ NBT, $1 \mathrm{U} / \mathrm{mL}$ diaphorase, $0.7 \%$ Tween 20 and $100 \mathrm{mM}$ Tris- $\mathrm{HCl}$ ( $\mathrm{pH} 8.0$ ) were dispensed into plates. After $10 \mathrm{~min}$ of incubation in the dark at room temperature, absorbance was measured at $630 \mathrm{~nm}$ with a vmax precision multiwell plate reader from Molecular Devices, by using the accompanying SOFT maxPro software for analysis. The inhibition percentage was calculated as described [8] and curve fitting was performed using Sigma Plot to yield the drug concentration that produced $50 \%$ of the observed decline from the maximum absorbance units in the drug-free control wells $\left(\mathrm{IC}_{50}\right)$. See curves in Figure $\mathrm{S} 2$ in Supplementary Materials.

\section{Results and Discussion}

\subsection{Chemistry}

3.1.1. General Procedures for the Synthesis of Intermediates Linker and Cationic Heads

The linkers (a-f, Scheme 1) were synthesized following the procedure previously reported [25-28]. The cationic heads were obtained following the procedure described [25,26,29]. See Spectra data in Figure S3 in Supplementary Materials.

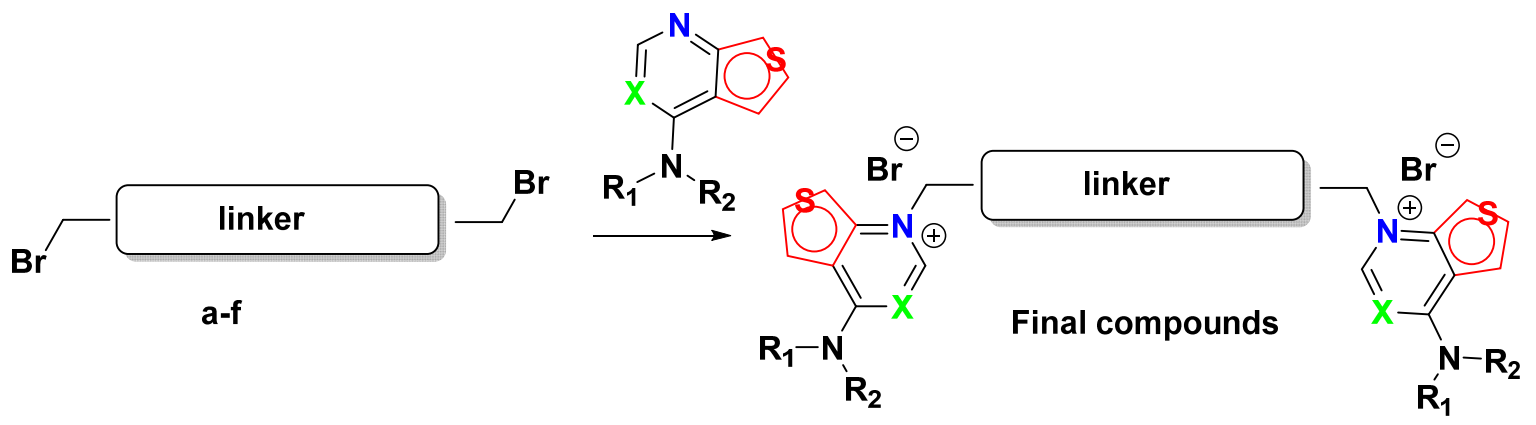

\footnotetext{
$X=C, N ; R_{1}=R_{2}=-C H_{3} ; R_{1}=R_{2}=\left(-C_{2}\right)_{4} ; R 1=R_{2}=\left(-C_{2}-\right) 5 ; R_{1}=R_{2}=\left(-C_{2}-\right) 6$; $\mathrm{R}_{1}=-\mathrm{CH}_{3} ; \mathrm{R}_{2}=-\mathrm{C}_{6} \mathrm{H}_{5} ; \mathrm{R}_{1}=-\mathrm{CH}_{3} ; \mathrm{R}_{2}=-\mathrm{p}-\mathrm{Cl}-\mathrm{C}_{6} \mathrm{H}_{4}$
}

Scheme 1. General synthetic pathway followed in the preparation of final compounds. a-f (1 equivalent), cationic head (2 equiv), $\mathrm{CH}_{3} \mathrm{CN}$, sealed tube $120 \mathrm{~h}$.

\subsubsection{General Procedure for the Synthesis of the Target Compounds}

A suspension of 1 equivalent of the linker and 2 equivalents of the corresponding cationic head in $\mathrm{CH}_{3} \mathrm{CN}$ was prepared in a sealed tube. The reaction mixture was stirred at $100{ }^{\circ} \mathrm{C}$ for 5 days. Afterwards, the cooled reaction was recrystallized by diethyl ether, filtered to obtain the final product as a solid without purification (Scheme 1).

4-([1,1'-biphenyl]-4-ylmethyl)-7-(pyrrolidin-1-yl)thieno[3,2-b]pyridin-4-ium bromide FM-a2. Following the general procedure, after workup as described previously, compound FM-a2 was isolated as a light-brown solid. Yield: $82 \%, \mathrm{mp}: 271-273{ }^{\circ} \mathrm{C} .{ }^{1} \mathrm{H} \mathrm{NMR}(400 \mathrm{MHz}$, $\left.\mathrm{CD}_{3} \mathrm{OD}\right) \delta 2.14(\mathrm{dd}, J=16.1,9.0 \mathrm{~Hz}, 4 \mathrm{H}), 3.71(\mathrm{~s}, 2 \mathrm{H}), 4.25(\mathrm{~s}, 2 \mathrm{H}), 5.70(\mathrm{~s}, 2 \mathrm{H}), 6.73(\mathrm{~d}$, $J=7.4 \mathrm{~Hz}, 1 \mathrm{H}), 7.32(\mathrm{pt}, 1 \mathrm{H}), 7.32-7.35(\mathrm{~m}, 2 \mathrm{H}), 7.38(\mathrm{~d}, J=7.3 \mathrm{~Hz}, 2 \mathrm{H}), 7.55(\mathrm{~d}, J=7.4 \mathrm{~Hz}$, 
2H), $7.61(\mathrm{~d}, J=8.2 \mathrm{~Hz}, 2 \mathrm{H}), 7.64(\mathrm{~d}, J=5.8 \mathrm{~Hz}, 1 \mathrm{H}), 8.28(\mathrm{~d}, J=5.8 \mathrm{~Hz}, 1 \mathrm{H}), 8.35(\mathrm{~d}$, $J=7.4 \mathrm{~Hz}, 1 \mathrm{H}) .{ }^{13} \mathrm{C}$ NMR $\left(101 \mathrm{MHz}, \mathrm{CD}_{3} \mathrm{OD}\right) \delta 24.12$ (1C), 25.79 (1C), 49.89 (1C), 50.69 (1C), 57.92 (1C), $101.94(1 \mathrm{C}), 117.29$ (1C), 120.82 (1C), 126.49 (2C), $127.32(1 \mathrm{C}), 127.34(2 \mathrm{C}), 127.39$ (2C), $128.51(2 \mathrm{C}), 133.39$ (1C), 136.01 (1C), 139.92 (1C), 141.58 (1C), 141.67 (1C), 145.90 (1C), 152.08 (1C). HRMS- $m / z(\mathrm{M})^{+}$calculated for $\mathrm{C}_{24} \mathrm{H}_{23} \mathrm{~N}_{2} \mathrm{~S}$ : 371.1582; found: 371.1585 .

1-([1,1'-biphenyl]-4-ylmethyl)-4-(pyrrolidin-1-yl)thieno[3,2-d]pyrimidin-1-ium bromide FMa1. Following the general procedure, after workup as described previously, compound FM-a1 was isolated as a yellow solid. Yield: $69 \%$, mp: $295-298{ }^{\circ} \mathrm{C}$. ${ }^{1} \mathrm{H} \mathrm{NMR}(500 \mathrm{MHz}$, $\left.\mathrm{CD}_{3} \mathrm{OD}\right) \delta$ 2.09-2.14 (m, 2H), 2.26-2.30 (m, 2H), 3.98-4.04 (m, 2H), 4.19-4.22 (m, 2H), 5.72 $(\mathrm{s}, 2 \mathrm{H}), 7.35(\mathrm{ddd}, J=1.5,2.0,7.0 \mathrm{~Hz}, 1 \mathrm{H}), 7.43(\mathrm{~m}, 2 \mathrm{H}), 7.47(\mathrm{~d}, J=8.5 \mathrm{~Hz}, 2 \mathrm{H}), 7.59(\mathrm{~d}$, $J=7.3 \mathrm{~Hz}, 2 \mathrm{H}), 7.63(\mathrm{~d}, J=5.7 \mathrm{~Hz}, 1 \mathrm{H}), 7.66(\mathrm{~d}, J=8.4 \mathrm{~Hz}, 2 \mathrm{H}), 8.45(\mathrm{~d}, J=5.7 \mathrm{~Hz}, 1 \mathrm{H})$, 8.90 (s, 1H). ${ }^{13} \mathrm{C}$ NMR (126 MHz, CD $\left.3 \mathrm{OD}\right) \delta 23.64$ (1C), 25.80 (1C), 49.30 (1C), 50.28 (1C), $55.23(1 \mathrm{C}), 116.82(1 \mathrm{C}), 117.19(1 \mathrm{C}), 126.54(2 \mathrm{C}), 127.41(1 \mathrm{C}), 127.45(2 \mathrm{C}), 127.62(2 \mathrm{C}), 128.56$ (2C), $132.72(1 \mathrm{C}), 138.71(1 \mathrm{C}), 139.90$ (1C), $141.81(1 \mathrm{C}), 146.19$ (1C), 149.89 (1C), 155.30 (1C). HRMS-m/z $(\mathrm{M})^{+}$calculated for $\mathrm{C}_{23} \mathrm{H}_{22} \mathrm{~N}_{3} \mathrm{~S}$ : 372.1534; found, 372.1564 .

1-([1,1'-biphenyl]-4-ylmethyl)-4-(pyrrolidin-1-yl)thieno[2,3-d]pyrimidin-1-ium bromide FMa3. Following the general procedure, after workup as described previously, compound FMa3 was isolated as a white-grey solid. Yield: $48 \%, \mathrm{mp}: 275-278{ }^{\circ} \mathrm{C} .{ }^{1} \mathrm{H}$ NMR $(400 \mathrm{MHz}, \mathrm{DMSO})$ $\delta$ 1.95-197 (m, 2H), 2.05-2.08 (m, 2H), $3.88(\mathrm{t}, J=6.8 \mathrm{~Hz}, 2 \mathrm{H}), 4.03(\mathrm{t}, J=6.8 \mathrm{~Hz}, 2 \mathrm{H})$, $5.70(\mathrm{~s}, 2 \mathrm{H}), 7.34(\mathrm{t}, J=7.3 \mathrm{~Hz}, 1 \mathrm{H}), 7.43(\mathrm{t}, J=7.5 \mathrm{~Hz}, 2 \mathrm{H}), 7.52(\mathrm{~d}, J=8.1,2 \mathrm{H}), 7.62(\mathrm{~d}$, $J=7.5 \mathrm{~Hz}, 2 \mathrm{H}), 7.69(\mathrm{~d}, J=8.2 \mathrm{~Hz}, 2 \mathrm{H}), 7.83(\mathrm{dd}, J=26.1,5.9 \mathrm{~Hz}, 2 \mathrm{H}), 9.20(\mathrm{~s}, 1 \mathrm{H}) .{ }^{13} \mathrm{C}$ NMR (101 MHz, DMSO) $\delta 23.91$ (1C), 26.24 (1C), 50.72 (1C), 51.15 (1C), 56.96 (1C), 117.39 (1C), $123.85(1 \mathrm{C}), 124.76(1 \mathrm{C}), 127.14(2 \mathrm{C}), 127.61(2 \mathrm{C}), 128.25(1 \mathrm{C}), 129.25(2 \mathrm{C}), 129.42(2 \mathrm{C})$, 132.22 (1C), 139.62 (1C), 141.15 (1C), 149.62 (1C), 153.39 (1C), 154.39 (1C). HRMS-m/z (M) ${ }^{+}$ calculated for $\mathrm{C}_{23} \mathrm{H}_{22} \mathrm{~N}_{3} \mathrm{~S}$ : 372.1534; found: 372.1551 .

1,1'-([1,1'-biphenyl]-4,4'-diylbis(methylene))bis(7-(pyrrolidin-1-yl)thieno[3,2-b]pyridin-4-ium) bromide $\mathbf{F g}$-9. Following the general procedure, after workup as described previously, compound Fg-9 was isolated as a yellow solid. Yield: $40 \%, \mathrm{mp}:>290{ }^{\circ} \mathrm{C} .{ }^{1} \mathrm{H} \mathrm{NMR}(500 \mathrm{MHz}$, $\left.\mathrm{CD}_{3} \mathrm{OD}\right) \delta 2.20(\mathrm{~d}, J=18.4 \mathrm{~Hz}, 8 \mathrm{H}), 3.75(\mathrm{~s}, 4 \mathrm{H}), 4.28(\mathrm{~s}, 4 \mathrm{H}), 5.73(\mathrm{~s}, 4 \mathrm{H}), 6.76(\mathrm{~d}, J=7.4 \mathrm{~Hz}$, $2 \mathrm{H}), 7.38(\mathrm{~d}, J=8.5 \mathrm{~Hz}, 4 \mathrm{H}), 7.62(\mathrm{~s}, 4 \mathrm{H}), 7.65(\mathrm{~d}, J=5.8 \mathrm{~Hz}, 2 \mathrm{H}), 8.30(\mathrm{~d}, J=5.8 \mathrm{~Hz}, 2 \mathrm{H}), 8.38$ (d, $J=7.4 \mathrm{~Hz}, 2 \mathrm{H}) .{ }^{13} \mathrm{C}$ NMR (101 MHz, CD $\left.\mathrm{OD}\right) \delta 24.27$ (4C), 25.81 (4C), 57.85 (2C), 101.96 (2C), $117.26(2 \mathrm{C}), 120.81(2 \mathrm{C}), 127.33$ (4C), 127.46 (4C), 133.98 (2C), 136.02 (2C), 140.45 (2C), 141.70 (2C), $145.88(2 \mathrm{C}), 152.09$ (2C). HRMS-m/z (M) ${ }^{+}$calculated for $\mathrm{C}_{36} \mathrm{H}_{36} \mathrm{~N}_{4} \mathrm{~S}_{2}$ : 588.237; found: 588.2347 .

1,1'-([1,1'-biphenyl]-4,4'-diylbis(methylene))bis(4-(pyrrolidin-1-yl)thieno[3,2-d]pyrimidin-1ium) bromide $\mathbf{F a - 2 1}$. Following the general procedure, after workup as described previously, compound Fa-21 was isolated as a yellow-lemon solid. Yield: 75\%, mp: $312-315{ }^{\circ} \mathrm{C} .{ }^{1} \mathrm{H}$ $\operatorname{NMR}\left(500 \mathrm{MHz}, \mathrm{CD}_{3} \mathrm{OD}\right) \delta 2.12(\mathrm{q}, J=6.9 \mathrm{~Hz}, 4 \mathrm{H}), 2.27(\mathrm{q}, J=6.9 \mathrm{~Hz}, 4 \mathrm{H}), 4.01(\mathrm{t}, J=7.0 \mathrm{~Hz}$, $4 \mathrm{H}), 4.21(\mathrm{t}, J=6.9 \mathrm{~Hz}, 4 \mathrm{H}), 5.73(\mathrm{~s}, 4 \mathrm{H}), 7.47(\mathrm{~d}, J=8.2 \mathrm{~Hz}, 4 \mathrm{H}), 7.61(\mathrm{~d}, J=5.7 \mathrm{~Hz}, 2 \mathrm{H})$, $7.65(\mathrm{~d}, J=8.3 \mathrm{~Hz}, 4 \mathrm{H}), 8.45(\mathrm{~d}, J=5.7 \mathrm{~Hz}, 2 \mathrm{H}), 8.91(\mathrm{~s}, 2 \mathrm{H}) .{ }^{13} \mathrm{C} \mathrm{NMR}\left(126 \mathrm{MHz}, \mathrm{CD}_{3} \mathrm{OD}\right)$

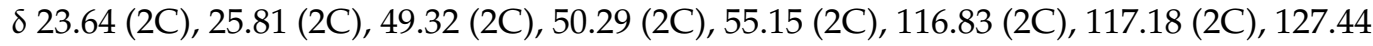
(4C), 127.76 (4C), 133.32 (2C), 138.74 (2C), 140.59 (2C), 146.16 (2C), 149.90 (2C), 155.29 (2C). HRMS- $m / z(\mathrm{M})^{2+}$ calculated for $\mathrm{C}_{34} \mathrm{H}_{34} \mathrm{~N}_{6} \mathrm{~S}_{2}$ : 590.2286; found: 590.2299.

1,1'-([1,1'-biphenyl]-4,4'-diylbis(methylene))bis(4-(pyrrolidin-1-yl)thieno[2,3-d]pyrimidin-1ium) bromide $\mathbf{F g}$-14. Following the general procedure, after workup as described previously, compound Fg-14 was isolated as a white solid. Yield: $70 \%, \mathrm{mp}: 300-302{ }^{\circ} \mathrm{C} .{ }^{1} \mathrm{H}$ NMR (400 MHz, DMSO) $\delta 1.95(\mathrm{dd}, J=13.4,6.7 \mathrm{~Hz}, 4 \mathrm{H}), 2.09(\mathrm{dt}, J=13.8,6.8 \mathrm{~Hz}, 4 \mathrm{H}), 3.87(\mathrm{t}$, $J=6.7 \mathrm{~Hz}, 4 \mathrm{H}), 4.03(\mathrm{t}, J=6.6 \mathrm{~Hz}, 4 \mathrm{H}), 5.69(\mathrm{~s}, 4 \mathrm{H}), 7.59(\mathrm{dd}, J=69.1,8.1 \mathrm{~Hz}, 8 \mathrm{H}), 7.83(\mathrm{dd}$, $J=27.0,5.9 \mathrm{~Hz}, 4 \mathrm{H}), 9.19$ (s, 2H). ${ }^{13} \mathrm{C}$ NMR (101 MHz, DMSO) $\delta 154.38$ (2C), 153.38 (2C), 149.63 (2C), $140.17(2 \mathrm{C}), 132.65$ (2C), 129.27 (4C), 124.29 (4C), $124.72(2 \mathrm{C}), 123.86(2 \mathrm{C}), 117.37$ (2C), 56.90 (2C), $51.16(2 \mathrm{C}), 50.65$ (2C), $26.24(2 \mathrm{C}), 23.91(2 \mathrm{C}) . \mathrm{HRMS}-m / z(\mathrm{M})^{+}$calculated for $\mathrm{C}_{34} \mathrm{H}_{34} \mathrm{~N}_{6} \mathrm{~S}_{2}$ : 590.2275; found: 590.2261.

1,1'-([1,1'-biphenyl]-4,4'-diylbis(methylene))bis(4-(piperidin-1-yl)thieno[3,2-d]pyrimidin-1-ium) bromide $\mathbf{F a - 2 4}$. Following the general procedure, after workup as described previously, com- 
pound Fa-24 was isolated as a yellow-lemon solid. Yield: $80.36 \%$, mp: $312-315{ }^{\circ} \mathrm{C} .{ }^{1} \mathrm{H}$ NMR (400 MHz, CD 3 OD) $\delta 1.83-186(\mathrm{~m}, 12 \mathrm{H}), 4.24(\mathrm{~d}, J=19.3 \mathrm{~Hz}, 8 \mathrm{H}), 5.72(\mathrm{~s}, 4 \mathrm{H}), 7.45$ $(\mathrm{d}, J=8.1 \mathrm{~Hz}, 4 \mathrm{H}), 7.61(\mathrm{~d}, J=5.9 \mathrm{~Hz}, 2 \mathrm{H}), 7.63(\mathrm{~d}, J=8.2 \mathrm{~Hz}, 4 \mathrm{H}), 8.40(\mathrm{~d}, J=5.8 \mathrm{~Hz}$, 2H), 8.90 (s, 2H). ${ }^{13} \mathrm{C} \mathrm{NMR}\left(101 \mathrm{MHz}, \mathrm{CD}_{3} \mathrm{OD}\right) \delta 23.44$ (2C), 25.61 (2C), 26.34 (2C), 47.77 (2C), $50.11(2 \mathrm{C}), 55.22(2 \mathrm{C}), 115.04(2 \mathrm{C}), 117.47$ (2C), $127.44(4 \mathrm{C}), 127.74(4 \mathrm{C}), 133.24(2 \mathrm{C})$, 138.09 (2C), 140.60 (2C), 147.50 (2C), 149.51 (2C), $155.82(2 \mathrm{C})$. HRMS-m/z (M) ${ }^{+}$calculated for $\mathrm{C}_{36} \mathrm{H}_{38} \mathrm{~N}_{6} \mathrm{~S}_{2}$ : 618.2599, found: 618.2609 .

1,1'-([1,1'-biphenyl]-4,4'-diylbis(methylene))bis(4-(piperidin-1-yl)thieno[2,3-d]pyrimidin-1-ium) bromide Fg-30. Following the general procedure, after workup as described previously, compound Fg-30 was isolated as a white solid. Yield: 57\%, mp: $388-290{ }^{\circ} \mathrm{C} .{ }^{1} \mathrm{H}$ NMR $(500 \mathrm{MHz}$, $\left.\mathrm{CD}_{3} \mathrm{OD}\right) \delta 1.95-1.97(\mathrm{~m}, 12 \mathrm{H}), 4.17(\mathrm{~s}, 4 \mathrm{H}), 4.29(\mathrm{~s}, 4 \mathrm{H}), 5.70(\mathrm{~s}, 4 \mathrm{H}), 7.63(\mathrm{~d}, J=8.3 \mathrm{~Hz}, 8 \mathrm{H})$, $7.78(\mathrm{~d}, J=6.0 \mathrm{~Hz}, 4 \mathrm{H}), 8.93(\mathrm{~s}, 2 \mathrm{H}) .{ }^{13} \mathrm{C} \mathrm{NMR}\left(126 \mathrm{MHz}, \mathrm{CD}_{3} \mathrm{OD}\right) \delta 23.39(6 \mathrm{C}), 50.35(2 \mathrm{C})$, 56.99 (4C), 116.26 (2C), 123.04 (2C), 124.42 (2C), 127.49 (4C), 128.69 (4C), $131.62(2 \mathrm{C}), 141.02$ (2C), 148.22 (2C), $154.83(2 \mathrm{C}), 155.99$ (2C). HRMS-m/z (M) calculated for $\mathrm{C}_{36} \mathrm{H}_{38} \mathrm{~N}_{8} \mathrm{~S}_{2}$ : 618.2588, found: 618.2568 .

1,1'-([1,1'-biphenyl]-4,4'-diylbis(methylene))bis(7-(azepan-1-yl)thieno[3,2-b]pyridin-4-ium) bromide $\mathbf{F g}$-10. Following the general procedure, after workup as described previously, compound Fg-10 was isolated as a white solid. Yield: 53\%, mp: $220-222{ }^{\circ} \mathrm{C} .{ }^{1} \mathrm{H}$ NMR $(600 \mathrm{MHz}$, $\left.\mathrm{CD}_{3} \mathrm{OD}\right) \delta 1.68(\mathrm{~s}, 8 \mathrm{H}), 2.01(\mathrm{~s}, 8 \mathrm{H}), 4,08(\mathrm{~s}, 8 \mathrm{H}), 5.76(\mathrm{~s}, 4 \mathrm{H}), 6.98(\mathrm{~d}, J=7.5 \mathrm{~Hz}, 2 \mathrm{H}), 7.38(\mathrm{~d}$, $J=8.1 \mathrm{~Hz}, 2 \mathrm{H}), 7.48(\mathrm{~d}, J=8.1 \mathrm{~Hz}, 2 \mathrm{H}), 7.57(\mathrm{~d}, J=8.2 \mathrm{~Hz}, 2 \mathrm{H}), 7.65(\mathrm{~d}, J=8.2 \mathrm{~Hz}, 2 \mathrm{H}), 7.68$ $(\mathrm{d}, J=5.9 \mathrm{~Hz}, 2 \mathrm{H}), 8.31(\mathrm{~d}, J=5.9 \mathrm{~Hz}, 2 \mathrm{H}), 8.40(\mathrm{~d}, J=7.5 \mathrm{~Hz}, 2 \mathrm{H}) .{ }^{13} \mathrm{C} \mathrm{NMR}(101 \mathrm{MHz}$, $\left.\mathrm{CD}_{3} \mathrm{OD}\right) \delta 26.11$ (4C), 32.23 (4C), 52.40 (4C), 58.08 (2C), 101.75 (2C), 117.41 (2C), 119.20 (2C), $126.62(2 \mathrm{C}), 127.39$ (2C), 127.50 (2C), $129.37(2 \mathrm{C}), 133.64(2 \mathrm{C}), 135.90(2 \mathrm{C}), 137.88(2 \mathrm{C})$, 139.89 (2C), 140.90 (2C), 141,71 (2C), 146.55 (2C), 154,18 (2C). HRMS-m/z (M) calculated for $\mathrm{C}_{40} \mathrm{H}_{44} \mathrm{~N}_{4} \mathrm{~S}_{2}$ : 644.2996; found: 644.3033 .

1,1'-([1,1'-biphenyl]-4,4'-diylbis(methylene))bis(4-(azepan-1-yl) thieno[2,3-d]pyrimidin-1ium) bromide $\mathbf{F a - 2 2}$. Following the general procedure, after workup as described previously, compound Fa-22 was isolated as a yellow-brown solid. Yield: $47.22 \%$, mp: $304-306{ }^{\circ} \mathrm{C} .{ }^{1} \mathrm{H}$ NMR (500 MHz, CD 30 OD) $\delta 1.69-171(m, 8 H), 1.96-197(\mathrm{~m}, 4 \mathrm{H}), 2.06-2.08(\mathrm{~m}, 4 \mathrm{H}), 4.21-4.23$ $(\mathrm{m}, 4 \mathrm{H}), 4.24-4.27(\mathrm{~m}, 4 \mathrm{H}), 5.74(\mathrm{~s}, 4 \mathrm{H}), 7.48(\mathrm{~d}, J=8.3 \mathrm{~Hz}, 4 \mathrm{H}), 7.63(\mathrm{~d}, J=5.8 \mathrm{~Hz}, 2 \mathrm{H}), 7.67$ $(\mathrm{d}, J=8.3 \mathrm{~Hz}, 4 \mathrm{H}), 8.46(\mathrm{~d}, J=5.8 \mathrm{~Hz}, 2 \mathrm{H}), 8.92(\mathrm{~s}, 2 \mathrm{H}) .{ }^{13} \mathrm{C} \mathrm{NMR}\left(126 \mathrm{MHz}, \mathrm{CD}_{3} \mathrm{OD}\right) \delta$ 26.08 (2C), 26.20 (2C), 26.31 (2C), 28.09 (2C), $50.34(2 \mathrm{C}), 51.35$ (2C), $55.24(2 \mathrm{C}), 115.28$ (2C), $117.28(2 \mathrm{C}), 127.49(4 \mathrm{C}), 127.77(4 \mathrm{C}), 133.23(2 \mathrm{C}), 138.73(2 \mathrm{C}), 140.66(2 \mathrm{C}), 147.05(2 \mathrm{C}), 149.45$ (2C), 157.11 (2C). HRMS- $m / z(\mathrm{M})^{+}$calculated for $\mathrm{C}_{38} \mathrm{H}_{42} \mathrm{~N}_{6} \mathrm{~S}_{2}$ : 646.2912, found: 646.2885.

1,1'-([1,1'-biphenyl]-4,4'-diylbis(methylene))bis(4-(azepan-1-yl)thieno[3,2-d]pyrimidin-1-ium) bromide $\mathbf{F g - 1 8}$. Following the general procedure, after workup as described previously, compound Fg-18 was isolated as a white solid. Yield: 74\%, mp: 303-305 ${ }^{\circ} \mathrm{C}$. ${ }^{1} \mathrm{H} \mathrm{NMR}(400 \mathrm{MHz}$, $\left.\mathrm{CD}_{3} \mathrm{OD}\right) \delta 1.68-1.66(\mathrm{~m}, 8 \mathrm{H}), 1.94(\mathrm{~s}, 4 \mathrm{H}), 2.01(\mathrm{~s}, 4 \mathrm{H}), 4.16-4.12(\mathrm{~m}, 4 \mathrm{H}), 4.21-4.17(\mathrm{~m}, 4 \mathrm{H})$, $5.68(\mathrm{~s}, 4 \mathrm{H}), 7.61(\mathrm{~d}, J=8.3 \mathrm{~Hz}, 8 \mathrm{H}), 7.76(\mathrm{~d}, J=6.0 \mathrm{~Hz}, 4 \mathrm{H}), 8.94(\mathrm{~s}, 2 \mathrm{H}) .{ }^{13} \mathrm{C} \mathrm{NMR}(101 \mathrm{MHz}$, $\left.\mathrm{CD}_{3} \mathrm{OD}\right) \delta 26.16(2 \mathrm{C}), 26.37$ (2C), $26.46(2 \mathrm{C}), 27.35$ (2C), $50.33(2 \mathrm{C}), 51.56(2 \mathrm{C}), 57.03(2 \mathrm{C})$, 116.37 (2C), 123.31 (2C), 123.67 (2C), 127.46 (4C), 128.69 (4C), 131.53 (2C), 140.9 (2C), 148.05 (2C), $154.54(2 \mathrm{C}), 156.60$ (2C). HRMS- $m / z(M)^{+}$calculated for $\mathrm{C}_{38} \mathrm{H}_{42} \mathrm{~N}_{6} \mathrm{~S}_{2}$ : 646.2901; found: 646.2908 .

1,1'-([1,1'-biphenyl]-4,4'-diylbis(methylene))bis(4-(methyl(phenyl)amino)thieno[3,2-d]pyrimidin-1ium)bromide $\mathbf{F} \boldsymbol{p}$-1. Following the general procedure, after workup as described previously, compound Fp-1 was isolated as a blue solid. Yield: $20 \%$, mp: $185-187{ }^{\circ} \mathrm{C} .{ }^{1} \mathrm{H}$ NMR (400 MHz, CD 3 OD) $\delta 3.84(\mathrm{~s}, 6 \mathrm{H}) .5 .80(\mathrm{~s}, 4 \mathrm{H}), 7.71-7.44(\mathrm{~m}, 20 \mathrm{H}), 8.14(\mathrm{~d}, J=5.7 \mathrm{~Hz}, 2 \mathrm{H})$, 9.16 (s, 2H). ${ }^{13} \mathrm{C} \mathrm{NMR}\left(101 \mathrm{MHz}, \mathrm{CD}_{3} \mathrm{OD}\right) \delta 41.78$ (2C), 57.05 (2C), 117.92 (2C), 128.23 (4C), $128.87(4 \mathrm{C}), 129.20(4 \mathrm{C}), 130.36(4 \mathrm{C}), 131.84(2 \mathrm{C}), 134.26(2 \mathrm{C}), 138.96(2 \mathrm{C}), 141.25(2 \mathrm{C})$, $141.77(2 \mathrm{C}), 142.52(2 \mathrm{C}), 148.62(2 \mathrm{C}), 151.66(2 \mathrm{C}), 159.00(2 \mathrm{C})$. HRMS-m/z (M) ${ }^{+}$calculated for $\mathrm{C}_{40} \mathrm{H}_{34} \mathrm{~N}_{6} \mathrm{~S}_{2}: 662.2286$, found: 662.2267 .

1,1'-([1,1'-biphenyl]-4,4'-diylbis(methylene))bis(4-((4-chlorophenyl)(methyl)amino)thieno[2,3d]pyrimidin-1-ium) bromide $\boldsymbol{F} \boldsymbol{p}-\mathbf{8}$. Following the general procedure, after workup as described previously, compound Fp-8 was isolated as a white solid. Yield: 40\%, mp: 
264-265 ${ }^{\circ} \mathrm{C} .{ }^{1} \mathrm{H}$ NMR (400 MHz, DMSO) $\delta 3.76$ (s, 6H), 5.81 (s, 4H), 7.74-7.57 (m, 20H), 9.44 (s, 2H). ${ }^{13} \mathrm{C}$ NMR (126 MHz, DMSO) $\delta 41.85$ (2C), 56.94 (2C), 117.33 (4C), 125.60 (2C), 127.27 (6C), 129.00 (8C), 130.74 (4C), 132.00 (2C), 139.82 (4C), 149.66 (2C), 154.25 (2C), 156.60 (2C). HRMS- $m / z(\mathrm{M})^{+}$calculated for $\mathrm{C}_{40} \mathrm{H}_{32} \mathrm{~N}_{6} \mathrm{~S}_{2} \mathrm{Cl}_{2}$ : 730.1507, found: 730.1520 .

4,4'-([2,2'-bipypidine]-5,5'-diylbis(methylene))bis(7-(pyrrolidin-1-yl)thieno[3,2-b]pyridin-4-ium bromide).Fg-12. Following the general procedure, after workup as described previously, compound Fg-12 was isolated as a purple solid. Yield: $60 \%, \mathrm{mp}$ : $>290{ }^{\circ} \mathrm{C}$. ${ }^{1} \mathrm{H} \mathrm{NMR}$ (400 MHz, DMSO) $\delta 2.05(\mathrm{~s}, 4 \mathrm{H}), 3.63(\mathrm{~s}, 4 \mathrm{H}), 4.09(\mathrm{~d}, J=28.6 \mathrm{~Hz}, 8 \mathrm{H}), 5.83(\mathrm{~s}, 4 \mathrm{H}), 6.80(\mathrm{~d}$, $J=7.4 \mathrm{~Hz}, 2 \mathrm{H}), 7.78(\mathrm{dd}, J=8.4,2.0 \mathrm{~Hz}, 2 \mathrm{H}), 7.82(\mathrm{~d}, J=5.8 \mathrm{~Hz}, 2 \mathrm{H}), 8.28(\mathrm{~d}, J=8.3 \mathrm{~Hz}, 2 \mathrm{H})$, $8.49(\mathrm{~d}, J=5.8 \mathrm{~Hz}, 2 \mathrm{H}), 8.61(\mathrm{~d}, J=7.4 \mathrm{~Hz}, 2 \mathrm{H}), 8.69(\mathrm{~d}, J=1.4 \mathrm{~Hz}, 2 \mathrm{H}) .{ }^{13} \mathrm{C} \mathrm{NMR}(101 \mathrm{MHz}$, DMSO) $\delta 24.41$ (2C), 26.36 (2C), 51.04 (2C), 51.47 (2C), 65.33 (2C) 102.99 (2C), 118.15 (2C), $120.55(2 \mathrm{C}), 120.98(2 \mathrm{C}), 132.09$ (2C), $136.65(2 \mathrm{C}), 137.66(2 \mathrm{C}), 142.59(2 \mathrm{C}), 145.78(2 \mathrm{C}), 148.85$ (2C), 151.85 (2C), 155.07 (2C). HRMS- $m / z(M)^{+}$calculated for $\mathrm{C}_{34} \mathrm{H}_{34} \mathrm{~N}_{6} \mathrm{~S}_{2}$ : 590.2275; found: 590.2247.

1,1'-([2,2'-bipyridine]-5,5'-diylbis(methylene))bis(4-(pyrrolidin-1-yl)thieno[3,2-d]pyrimidin1-ium) bromide Fg-17. Following the general procedure, after workup as described previously, compound Fg-17 was isolated as a yellow solid. Yield: $62 \%$, mp: $330-332{ }^{\circ} \mathrm{C} .{ }^{1} \mathrm{H}$ $\operatorname{NMR}\left(400 \mathrm{MHz}, \mathrm{CD}_{3} \mathrm{OD}\right) \delta 2.09(\mathrm{q}, J=6.8 \mathrm{~Hz}, 4 \mathrm{H}), 2.25(\mathrm{q}, J=6.8 \mathrm{~Hz}, 4 \mathrm{H}), 3.99$ (t, $J=6.9 \mathrm{~Hz}$, $4 \mathrm{H}), 4.19(\mathrm{t}, J=6.9 \mathrm{~Hz}, 4 \mathrm{H}), 5.79(\mathrm{~s}, 4 \mathrm{H}), 7.63(\mathrm{~d}, J=5.7 \mathrm{~Hz}, 2 \mathrm{H}), 7.90(\mathrm{dd}, J=8.3,2.0 \mathrm{~Hz}$, $2 \mathrm{H}), 8.35(\mathrm{~d}, J=8.3 \mathrm{~Hz}, 2 \mathrm{H}), 8.45(\mathrm{~d}, J=5.7 \mathrm{~Hz}, 2 \mathrm{H}), 8.72(\mathrm{~d}, J=1.5 \mathrm{~Hz}, 2 \mathrm{H}), 8.91(\mathrm{~s}, 2 \mathrm{H})$. ${ }^{13} \mathrm{C}$ NMR (101 MHz, CD $\left.\mathrm{OD}\right) \delta 23.61$ (2C), 25.77 (2C), 49.35 (2C), 50.33 (2C), 52.77 (2C), $116.87(2 \mathrm{C}), 121.13(2 \mathrm{C}), 130.57$ (2C), 136.20 (4C), 138.98 (2C), 145.89 (2C), $148.16(2 \mathrm{C}), 149.96$ (2C), 155.29 (2C), 155.35 (2C). HRMS- $m / z(M)^{+}$calculated for $\mathrm{C}_{32} \mathrm{H}_{32} \mathrm{~N}_{8} \mathrm{~S}_{2}$ : 592.2180; found: 592.2235 .

1,1'-([2,2'-bipyridine]-5,5'-diylbis(methylene))bis(4-(pyrrolidin-1-yl)thieno[2,3-d]pyrimidin1-ium) bromide $\mathbf{F g - 1 3}$. Following the general procedure, after workup as described previously, compound Fg-13 was isolated as a white solid. Yield: 71\%, mp: $238-240{ }^{\circ} \mathrm{C}$. ${ }^{1} \mathrm{H}$ NMR (400 MHz, DMSO) $\delta$ 2.14-1.91 (m, 8H), $3.87(\mathrm{t}, J=6.9 \mathrm{~Hz}, 4 \mathrm{H}), 4.03(\mathrm{t}, J=6.9 \mathrm{~Hz}, 4 \mathrm{H})$, $5.79(\mathrm{~s}, 2 \mathrm{H}), 7.80(\mathrm{~d}, J=5.9 \mathrm{~Hz}, 2 \mathrm{H}), 7.87(\mathrm{~d}, J=5.9 \mathrm{~Hz}, 2 \mathrm{H}), 8.01(\mathrm{dd}, J=8.3,2.3 \mathrm{~Hz}, 2 \mathrm{H})$, $8.35(\mathrm{~d}, J=8.3 \mathrm{~Hz}, 2 \mathrm{H}), 8.83(\mathrm{~d}, J=2.3 \mathrm{~Hz}, 2 \mathrm{H}), 9.21(\mathrm{~s}, 2 \mathrm{H}) .{ }^{13} \mathrm{C}$ NMR $(101 \mathrm{MHz}, \mathrm{DMSO})$ $\delta 23.91$ (2C), 26.24 (2C), 50.75 (2C), 51.18 (2C), 54.67 (2C), 117.43 (2C), 121.04 (2C), 123.96 (2C), $124.62(2 \mathrm{C}), 129.78(2 \mathrm{C}), 137.72(2 \mathrm{C}), 149.75(2 \mathrm{C}), 155.44(2 \mathrm{C}), 149.86(2 \mathrm{C}), 153.25$ (2C), 154.41 (2C). HRMS-m/z (M) calculated for $\mathrm{C}_{32} \mathrm{H}_{32} \mathrm{~N}_{8} \mathrm{~S}_{2}$ : 592.2180; found: 592.2200 .

1,1'-([2,2'-bipyridine]-5,5'-diylbis(methylene))bis(4-(piperidin-1-yl)thieno[3,2-d]pyrimidin-1ium) bromide $\mathbf{F a}$-27. Following the general procedure, after workup as described previously, compound Fa-27 was isolated as a yellow-brown solid. Yield: 58\%, mp: 307-309 ${ }^{\circ} \mathrm{C} .{ }^{1} \mathrm{H}$ NMR (500 MHz, CD 3 OD) $\delta$ 1.86-189 (m, 12H), 4.29-4.27 (m, 8H), $5.84(\mathrm{~s}, 4 \mathrm{H}), 7.68(\mathrm{~d}$, $J=5.8 \mathrm{~Hz}, 2 \mathrm{H}), 7.93(\mathrm{dd}, J=8.3,2.2 \mathrm{~Hz}, 2 \mathrm{H}), 8.38(\mathrm{~d}, J=8.3 \mathrm{~Hz}, 2 \mathrm{H}), 8.46(\mathrm{~d}, J=5.8 \mathrm{~Hz}, 2 \mathrm{H})$, $8.76(\mathrm{~d}, J=2.0 \mathrm{~Hz}, 2 \mathrm{H}), 8.96(\mathrm{~s}, 2 \mathrm{H}) .{ }^{13} \mathrm{C} \mathrm{NMR}\left(126 \mathrm{MHz}, \mathrm{CD}_{3} \mathrm{OD}\right) \delta 23.45(2 \mathrm{C}), 25.62(2 \mathrm{C})$, 26.35 (2C), 47.81 (2C), 50.19 (2C), 52.90 (2C), $115.16(2 \mathrm{C}), 117.24(2 \mathrm{C}), 121.18(2 \mathrm{C}), 130.55$ (2C), 136.28 (2C), 138.38 (2C), 147.30 (2C), 148.22 (2C), 149.62 (2C), 155.50 (2C), 155.85 (2C). HRMS- $m / z(\mathrm{M})^{+}$calculated for $\mathrm{C}_{34} \mathrm{H}_{36} \mathrm{~N}_{8} \mathrm{~S}_{2}$ : 620.2504, found: 620.2446.

1,1'-([2,2'-bipyridine]-5,5'-diylbis(methylene))bis(4-(piperidin-1-yl)thieno[2,3-d]pyrimidin-1ium) bromide $\mathbf{F g}-\mathbf{3 2}$. Following the general procedure, after workup as described previously, compound Fg-32 was isolated as a white solid. Yield: 64\%, mp: $267-269 \mathrm{C}^{\circ} .{ }^{1} \mathrm{H}$ NMR $\left(400 \mathrm{MHz}, \mathrm{CD}_{3} \mathrm{OD}\right) \delta 8.94(\mathrm{~s}, 2 \mathrm{H}), 8.81(\mathrm{~s}, 2 \mathrm{H}), 8.41(\mathrm{~d}, J=8.2 \mathrm{~Hz}, 2 \mathrm{H}), 8.01(\mathrm{~d}, J=8.2 \mathrm{~Hz}, 2 \mathrm{H})$, $7.76(\mathrm{~d}, J 5.9 \mathrm{~Hz}, 4 \mathrm{H}), 5.76(\mathrm{~s}, 4 \mathrm{H}), 4.27(\mathrm{~s}, 4 \mathrm{H}), 4.14(\mathrm{~s}, 4 \mathrm{H}), 1.84(\mathrm{~s}, 12 \mathrm{H}) .{ }^{13} \mathrm{C} \mathrm{NMR}(101 \mathrm{MHz}$, $\left.\mathrm{CD}_{3} \mathrm{OD}\right) \delta 155.95$ (2C), 155.80 (2C), 154.55 (2C), 149.07 (2C), 148.31 (2C), 137.05 (2C), 129.01 (2C), $123.36(2 \mathrm{C}), 123.23(2 \mathrm{C}), 121.20(2 \mathrm{C}), 116.29(2 \mathrm{C}), 54.53(2 \mathrm{C}), 50.23(2 \mathrm{C}), 24.93(2 \mathrm{C})$, 23.34 (6C). HRMS- $m / z(\mathrm{M})^{+}$calculated for $\mathrm{C}_{34} \mathrm{H}_{36} \mathrm{~N}_{8} \mathrm{~S}_{2}$ : 620.2493; found: 620.2459 .

1,1'-([2,2'-bipyridine]-5,5'-diylbis(methylene))bis(4-(azepan-1-yl)thieno[3,2-d]pyrimidin-1-ium) bromide $\mathbf{F a}$-26. Following the general procedure, after workup as described previously, compound Fa-26 was isolated as a light brown solid. Yield: $20 \%, \mathrm{mp}: 310-312{ }^{\circ} \mathrm{C} .{ }^{1} \mathrm{H}$ NMR (400 MHz, CD 3 OD) $\delta$ 1.67-1.69 (m, 8H), 1.96-198 (m, 4H), 2.02-2.04 (m, 4H), 4.20-4.22 (m, 
$8 \mathrm{H}), 5.80(\mathrm{~s}, 4 \mathrm{H}), 7.64(\mathrm{~d}, J=5.8 \mathrm{~Hz}, 2 \mathrm{H}), 7.91(\mathrm{~d}, J=8.0 \mathrm{~Hz}, 2 \mathrm{H}), 8.36(\mathrm{~d}, J=8.3 \mathrm{~Hz}, 2 \mathrm{H})$, $8.46(\mathrm{~d}, J=5.8 \mathrm{~Hz}, 2 \mathrm{H}), 8.73(\mathrm{~d}, J=1.3 \mathrm{~Hz}, 2 \mathrm{H}), 8.92(\mathrm{~s}, 2 \mathrm{H}) .{ }^{13} \mathrm{C}$ NMR $\left(126 \mathrm{MHz}, \mathrm{CD}_{3} \mathrm{OD}\right) \delta$ 26.07 (2C), 26.19 (2C), $26.31(2 \mathrm{C}), 28.04(2 \mathrm{C}), 50.38(2 \mathrm{C}), 51.40(2 \mathrm{C}), 52.89(2 \mathrm{C}), 115.39(2 \mathrm{C})$, 117.02 (2C), 121.18 (2C), 130.51 (2C), 136.29 (2C), 139.00 (2C), 146.82 (2C), 148.23 (2C), 149.54 (2C), $155.51(2 \mathrm{C}), 157.12(2 \mathrm{C})$. HRMS $-m / z(\mathrm{M})^{+}$calculated for $\mathrm{C}_{36} \mathrm{H}_{40} \mathrm{~N}_{8} \mathrm{~S}_{2}$ : 648.2817, found: 648.2833.

1,1'-([2,2'-bipyridine]-5,5'-diylbis(methylene))bis(4-(azepan-1-yl)thieno[2,3-d]pyrimidin-1-ium) bromide Fg-20. Following the general procedure, after workup as described previously, compound Fg-20 was isolated as a white solid. Yield: 68\%, mp: $289-291{ }^{\circ} \mathrm{C} .{ }^{1} \mathrm{H}$ NMR $(500 \mathrm{MHz}$, $\left.\mathrm{CD}_{3} \mathrm{OD}\right) \delta 1.74-1.66(\mathrm{~m}, 8 \mathrm{H}), 2.00-1.94(\mathrm{~m}, 4 \mathrm{H}), 2.08-2.01(\mathrm{~m}, 4 \mathrm{H}), 4.19-4.16(\mathrm{~m}, 4 \mathrm{H}), 4.24-$ $4.21(\mathrm{~m}, 4 \mathrm{H}), 5.81(\mathrm{~s}, 4 \mathrm{H}), 7.75(\mathrm{~d}, J=6.0 \mathrm{~Hz}, 2 \mathrm{H}), 7.84(\mathrm{~d}, J=6.0 \mathrm{~Hz}, 2 \mathrm{H}), 8.04(\mathrm{dd}, J=8.3$, $2.3 \mathrm{~Hz}, 2 \mathrm{H}), 8.44(\mathrm{~d}, J=8.3 \mathrm{~Hz}, 2 \mathrm{H}), 8.84(\mathrm{~d}, J=2.1 \mathrm{~Hz}, 2 \mathrm{H}), 8.96(\mathrm{~s}, 2 \mathrm{H}) .{ }^{13} \mathrm{C} \mathrm{NMR}(126 \mathrm{MHz}$, $\left.\mathrm{CD}_{3} \mathrm{OD}\right) \delta 26.40(4 \mathrm{C}), 26.48$ (2C), 27.35 (2C), 50.39 (2C), $51.63(2 \mathrm{C}), 54.63(2 \mathrm{C}), 116.48(2 \mathrm{C})$, $121.24(2 \mathrm{C}), 123.16(2 \mathrm{C}), 123.92(2 \mathrm{C}), 128.97(2 \mathrm{C}), 137.10(2 \mathrm{C}), 148.20(2 \mathrm{C}), 149.12(2 \mathrm{C}), 154.33$ (2C), 155.83 (2C), 156.64 (2C). HRMS- $m / z(M)^{+}$calculated for $\mathrm{C}_{36} \mathrm{H}_{40} \mathrm{~N}_{8} \mathrm{~S}_{2}$ : 648.2806; found: 648.2794 .

4,4'-((ethane-1,2-diylbis(4,1-phenylene))bis(methylene))bis(7-(pyrrolidin-1-yl)thieno[3,2-b]pyridin4-ium) bromide Fg-11. Following the general procedure, after workup as described previously, compound Fg-11 was isolated as a white solid. Yield: $68 \%$, mp: $253-255{ }^{\circ} \mathrm{C} .{ }^{1} \mathrm{H}$ NMR $\left(400 \mathrm{MHz}, \mathrm{CD}_{3} \mathrm{OD}\right) \delta 2.17(\mathrm{~s}, 8 \mathrm{H}), 3.29(\mathrm{dt}, J=3.2,1.6 \mathrm{~Hz}, 2 \mathrm{H}), 3.33(\mathrm{~s}, 2 \mathrm{H}), 3,71(\mathrm{~s}, 4 \mathrm{H})$, $4.25(\mathrm{~s}, 4 \mathrm{H}), 5.61(\mathrm{~s}, 4 \mathrm{H}), 6.71(\mathrm{~d}, J=7.4 \mathrm{~Hz}, 2 \mathrm{H}), 7.15(\mathrm{~s}, 8 \mathrm{H}), 7.58(\mathrm{~d}, J=5.8 \mathrm{~Hz}, 2 \mathrm{H}), 8.27$ $(\mathrm{d}, J=5.8 \mathrm{~Hz}, 2 \mathrm{H}), 8.29(\mathrm{~d}, J=7.4 \mathrm{~Hz}, 2 \mathrm{H}) .{ }^{13} \mathrm{C} \mathrm{NMR}\left(126 \mathrm{MHz}, \mathrm{CD}_{3} \mathrm{OD}\right) \delta 24.05(4 \mathrm{C})$, 25.69 (4C), 36.88 (1C), 50.71 (1C), 58.04 (2C), 101.90 (2C), 117.29 (2C), $120.81(2 \mathrm{C}), 126.92$ (4C), $129.00(4 \mathrm{C}), 132.08(2 \mathrm{C}), 135.92(2 \mathrm{C}), 141.63(2 \mathrm{C}), 141.96(2 \mathrm{C}), 145.91(2 \mathrm{C}), 152.08(2 \mathrm{C})$ HRMS- $m / z(\mathrm{M})^{+}$calculated for $\mathrm{C}_{38} \mathrm{H}_{40} \mathrm{~N}_{4} \mathrm{~S}_{2}$ : 616.2683; found: 616.2717.

1,1'-((ethane-1,2-diylbis(4,1-phenylene))bis(methylene))bis(4-(pyrrolidin-1-yl)thieno[3,2-d]pyrimidin1-ium) bromide Fg-16. Following the general procedure, after workup as described previously, compound Fg-16 was isolated as a yellow solid. Yield: $72 \%$, mp: $231-233{ }^{\circ} \mathrm{C} .{ }^{1} \mathrm{H}$ NMR $\left(400 \mathrm{MHz}, \mathrm{CD}_{3} \mathrm{OD}\right) \delta 2.09$ (d, $\left.J=6.8 \mathrm{~Hz}, 4 \mathrm{H}\right), 2.24(\mathrm{~d}, J=6.8 \mathrm{~Hz}, 4 \mathrm{H}), 2.85$ (s, 2H), 3.29 $(\mathrm{dt}, J=3.0,1.5 \mathrm{~Hz}, 2 \mathrm{H}), 3.98(\mathrm{t}, J=7.0 \mathrm{~Hz}, 4 \mathrm{H}), 4.18(\mathrm{t}, J=6.9 \mathrm{~Hz}, 4 \mathrm{H}), 5.60(\mathrm{~s}, 4 \mathrm{H}), 7.20$ $(\mathrm{d}, J=8.1 \mathrm{~Hz}, 4 \mathrm{H}), 7,24(\mathrm{~d}, J=8,1 \mathrm{~Hz}, 4 \mathrm{H}), 7.54(\mathrm{~d}, J=5.7 \mathrm{~Hz}, 2 \mathrm{H}), 8.42(\mathrm{~d}, J=5.7 \mathrm{~Hz}$, 2H), $8.81(\mathrm{~s}, 2 \mathrm{H}) .{ }^{13} \mathrm{C} \mathrm{NMR}\left(101 \mathrm{MHz}, \mathrm{CD}_{3} \mathrm{OD}\right) \delta 23.61$ (4C), $25.78(2 \mathrm{C}), 36.81(2 \mathrm{C}), 49.28$ (1C), $50.23(1 \mathrm{C}), 55.31(2 \mathrm{C}), 116.77(2 \mathrm{C}), 117.16(2 \mathrm{C}), 127.15(4 \mathrm{C}), 129.09$ (4C), 131.31 (2C), 138.62 (2C), 142.42 (2C), 146.16 (2C), 149.75 (2C), 155.25 (2C). HRMS-m/z (M) ${ }^{+}$calculated for $\mathrm{C}_{36} \mathrm{H}_{38} \mathrm{~N}_{6} \mathrm{~S}_{2}$ : 618.2588; found: 618.2586 .

1,1'-((ethane-1,2-diylbis(4,1-phenylene))bis(methylene))bis(4-(pyrrolidin-1-yl)thieno[2,3d]pyrimidin-1-ium) bromide Fg-15. Following the general procedure, after workup as described previously, compound Fg-15 was isolated as a white solid. Yield: 80\%, mp: 293-295 ${ }^{\circ} \mathrm{C} .{ }^{1} \mathrm{H}$ NMR $\left(400 \mathrm{MHz}, \mathrm{CD}_{3} \mathrm{OD}\right) \delta 2.10$ (q, J = 6.9 Hz, 2H), $2.23(\mathrm{q}, J=6.9 \mathrm{~Hz}, 2 \mathrm{H})$, $2.88(\mathrm{~s}, 4 \mathrm{H}), 4.00(\mathrm{t}, J=6.9 \mathrm{~Hz}, 4 \mathrm{H}), 4.11(\mathrm{t}, J=6.9 \mathrm{~Hz}, 4 \mathrm{H}), 5.56(\mathrm{~s}, 4 \mathrm{H}), 7.19(\mathrm{~d}, J=8.0 \mathrm{~Hz}$, $4 \mathrm{H}), 7.30(\mathrm{~d}, J=8.0 \mathrm{~Hz}, 4 \mathrm{H}), 7.79(\mathrm{~d}, J=6.0 \mathrm{~Hz}, 2 \mathrm{H}), 7.88(\mathrm{~d}, J=6.0 \mathrm{~Hz}, 2 \mathrm{H}), 8.86(\mathrm{~s}, 2 \mathrm{H}) .{ }^{13} \mathrm{C}$ NMR (126 MHz, CD 3 OD) $\delta 23.43$ (4C), 25.88 (2C), 36.90 (2C), 50.33 (1C), 50.78 (1C), 57.19 (2C), $117.34(2 \mathrm{C}), 123.08$ (2C), 123.29 (2C), 128.06 (4C), 129.16 (4C), 129.57 (2C), 142.98 (2C), 148.42 (2C), $153.48(2 \mathrm{C}), 154.51(2 \mathrm{C})$. HRMS- $m / z(\mathrm{M})^{+}$calculated for $\mathrm{C}_{36} \mathrm{H}_{38} \mathrm{~N}_{6} \mathrm{~S}_{2}$ : 618.2588 ; found: 618.2586 .

1,1'-((ethane-1,2-diylbis(4,1-phenylene))bis(methylene))bis(4-(piperidin-1-yl)thieno[3,2-d]pyrimidin1-ium) bromide $\mathbf{F a - 2 5}$. Following the general procedure, after workup as described previously, compound Fa-25 was isolated as a yellow-brown solid. Yield: $76 \%$, mp: $314-316{ }^{\circ} \mathrm{C} .{ }^{1} \mathrm{H}$ NMR (400 MHz, CD 3 OD) $\delta$ 1.82-1.85 (m, 12H), 2.84-2.87 (s, 4H), 4.24-4.27 (m, 8H), 5.62 $(\mathrm{s}, 4 \mathrm{H}), 7.19(\mathrm{~d}, J=8.1 \mathrm{~Hz}, 4 \mathrm{H}), 7.25(\mathrm{~d}, J=8.1 \mathrm{~Hz}, 4 \mathrm{H}), 7.57(\mathrm{~d}, J=5.8 \mathrm{~Hz}, 2 \mathrm{H}), 8.40(\mathrm{~d}$, $J=5.7 \mathrm{~Hz}, 2 \mathrm{H}), 8.83(\mathrm{~s}, 2 \mathrm{H}) .{ }^{13} \mathrm{C}$ NMR $\left(101 \mathrm{MHz}, \mathrm{CD}_{3} \mathrm{OD}\right) \delta 23.48(2 \mathrm{C}), 25.70(2 \mathrm{C}), 26.42$ (2C), $36.88(2 \mathrm{C}), 47.75(2 \mathrm{C}), 50.11(2 \mathrm{C}), 55.52(2 \mathrm{C}), 114.99(2 \mathrm{C}), 117.56(2 \mathrm{C}), 127.27(4 \mathrm{C}), 129.18$ (4C), 131.10 (2C), 138.17 (2C), 142.50 (2C), 147.55 (2C), 149.34 (2C), 155.78 (2C). HRMS-m/z $(\mathrm{M})^{+}$calculated for $\mathrm{C}_{38} \mathrm{H}_{42} \mathrm{~N}_{6} \mathrm{~S}_{2}: 646.2912$, found: 646.2922 . 
1,1'-((ethane-1,2-diylbis(4,1-phenylene))bis(methylene))bis(4-(piperidin-1-yl)thieno[2,3-d]pyrimidin1-ium) bromide $\mathbf{F g}$-31. Following the general procedure, after workup as described previously, compound Fg-31 was isolated as a white solid. Yield: $85 \%$, mp: $295-297{ }^{\circ} \mathrm{C}$. ${ }^{1} \mathrm{H}$ NMR (400 MHz, CD 3 OD) $\delta 1.83-1.85$ (s, 12H), 2.88 (s, 2H), 3.29 (s, 2H), $4.13(\mathrm{~s}, 4 \mathrm{H}), 4.25$ (s, 4H), $5.56(\mathrm{~s}, 4 \mathrm{H}), 7.32(\mathrm{dd}, J=7.9 \mathrm{~Hz}, 8 \mathrm{H}), 7.75(\mathrm{dd}, J=19.1,5.9 \mathrm{~Hz}, 4 \mathrm{H}), 8.84(\mathrm{~s}, 2 \mathrm{H}) .{ }^{13} \mathrm{C} \mathrm{NMR}$ (101 MHz, CD 3 OD) $\delta 23.36$ (6C), 25.90 (2C), 36.87 (2C), 50.17 (2C) 57.17 (2C), 116.22 (2C), 122.95 (2C), 123.57 (2C), 128.10 (4C), 129.14 (4C), 129.53 (2C), 142.97 (2C), 148.07 (2C), 154.79 (2C), 155.95 (2C). HRMS- $m / z(\mathrm{M})^{+}$calculated for $\mathrm{C}_{38} \mathrm{H}_{42} \mathrm{~N}_{6} \mathrm{~S}_{2}$ : 646.2901; found: 646.2946.

1,1'-((ethane-1,2-diylbis(4,1-phenylene))bis(methylene))bis(4-(azepan-1-yl)thieno[3,2-d]pyrimidin1-ium) bromide $\mathbf{F a - 2 3 . ~ F o l l o w i n g ~ t h e ~ g e n e r a l ~ p r o c e d u r e , ~ a f t e r ~ w o r k u p ~ a s ~ d e s c r i b e d ~ p r e v i o u s l y , ~}$ compound Fa-23 was isolated as a yellow-orange solid. Yield: 81\%, mp: 321-323 ${ }^{\circ} \mathrm{C} .{ }^{1} \mathrm{H}$ NMR (500 MHz, CD 3 OD) $\delta 1.67-1.70(\mathrm{~m}, 8 \mathrm{H}), 1.95-1.98(\mathrm{~m}, 4 \mathrm{H}), 2.05-2.07$ (m, 4H), 2.89 $(\mathrm{s}, 4 \mathrm{H}), 4.21(\mathrm{t}, J=6 \mathrm{~Hz}, 4 \mathrm{H}), 4.25(\mathrm{t}, J=6 \mathrm{~Hz}, 4 \mathrm{H}), 5.65(\mathrm{~s}, 4 \mathrm{H}), 7.22(\mathrm{~d}, J=8.2 \mathrm{~Hz}, 4 \mathrm{H})$, $7.29(\mathrm{~d}, J=8.2 \mathrm{~Hz}, 4 \mathrm{H}), 7.59(\mathrm{~d}, J=5.8 \mathrm{~Hz}, 2 \mathrm{H}), 8.47(\mathrm{t}, J=5.9 \mathrm{~Hz}, 2 \mathrm{H}), 8.87(\mathrm{~s}, 2 \mathrm{H}) .{ }^{13} \mathrm{C}$ NMR (126 MHz, CD 3 OD) $\delta 26.09$ (2C), 26.21 (2C), 26.32 (2C), 28.11 (2C), 36.86 (2C), 50.31 (2C), $51.34(2 \mathrm{C}), 55.44(2 \mathrm{C}), 115.25(2 \mathrm{C}), 117.33(2 \mathrm{C}), 127.24(4 \mathrm{C}), 129.14(4 \mathrm{C}), 131.26(2 \mathrm{C})$, $138.66(2 \mathrm{C}), 142.52(2 \mathrm{C}), 147.07(2 \mathrm{C}), 149.34(2 \mathrm{C}), 157.09(2 \mathrm{C})$. HRMS-m/z $(\mathrm{M})^{+}$calculated for $\mathrm{C}_{40} \mathrm{H}_{46} \mathrm{~N}_{6} \mathrm{~S}_{2}: 674.3225$, found: 674.3286 .

1,1'-((ethane-1,2-diylbis(4,1-phenylene))bis(methylene))bis(4-(azepan-1-yl)thieno[2,3-d]pyrimidin1-ium) bromide $\mathbf{F g}$-19. Following the general procedure, after workup as described previously, compound Fg-19 was isolated as a white solid. Yield: $78 \%$, mp: $298-300{ }^{\circ} \mathrm{C}$. ${ }^{1} \mathrm{H}$ NMR (500 MHz, CD 3 OD) $\delta 1.69-1.71(\mathrm{~m}, 8 \mathrm{H}), 2.02-2.06(\mathrm{~s}, 8 \mathrm{H}), 2.92(\mathrm{~s}, 4 \mathrm{H}), 4.18-4.15(\mathrm{~m}, 4 \mathrm{H})$, 4.23-4.19 (m, 4H), $5.60(\mathrm{~s}, 4 \mathrm{H}), 7.24(\mathrm{~d}, J=8.1 \mathrm{~Hz}, 4 \mathrm{H}), 7.35(\mathrm{~d}, J=8.1 \mathrm{~Hz}, 4 \mathrm{H}), 7.79(\mathrm{~d}$, $J=6.0 \mathrm{~Hz}, 2 \mathrm{H}), 7.81(\mathrm{~d}, 6.0 \mathrm{~Hz}, 2 \mathrm{H}), 8.89(\mathrm{~s}, 2 \mathrm{H}) .{ }^{13} \mathrm{C} \mathrm{NMR}\left(101 \mathrm{MHz}, \mathrm{CD}_{3} \mathrm{OD}\right) \delta 26.18(2 \mathrm{C})$, 26.39 (2C), $26.48(2 \mathrm{C}), 27.38(2 \mathrm{C}), 36.92(2 \mathrm{C}), 50.34(2 \mathrm{C}), 51.56(2 \mathrm{C}), 57.24(2 \mathrm{C}), 116.38(2 \mathrm{C})$, $123.33(2 \mathrm{C}), 123.64(2 \mathrm{C}), 128.13(4 \mathrm{C}), 129.16(4 \mathrm{C}), 129.49$ (2C), $143.04(2 \mathrm{C}), 147.96(2 \mathrm{C}), 154.56$ (2C), $156.62(2 \mathrm{C})$. HRMS- $m / z(\mathrm{M})^{+}$calculated for $\mathrm{C}_{40} \mathrm{H}_{46} \mathrm{~N}_{6} \mathrm{~S}_{2}$ : 646.3214; found: 646.3174 .

4,4'-((butane-1,4-diylbis(4,1-phenylene))bis(methylene))bis(7-(pyrrolidin-1-yl)thieno[3,2-b]pyridin4-ium) bromide $\mathbf{F f - 1}$. Following the general procedure, after workup as described previously, compound Ff-1 was isolated as a white solid. Yield: $17 \%, \mathrm{mp}: 195-197{ }^{\circ} \mathrm{C} .{ }^{1} \mathrm{H}$ NMR (400 MHz, CD 3 OD) $\delta 1.61(\mathrm{~s}, 4 \mathrm{H}), 2.14-2.16(\mathrm{~m}, 8 \mathrm{H}), 2.62(\mathrm{~s}, 4 \mathrm{H}), 3.75-3.78(\mathrm{~m}, 4 \mathrm{H})$, 4.29-4.32 (m, 4H), $5.67(\mathrm{~s}, 4 \mathrm{H}), 6.77(\mathrm{~d}, J=7.4 \mathrm{~Hz}, 2 \mathrm{H}), 7.20(\mathrm{~d}, J=8.3 \mathrm{~Hz}, 4 \mathrm{H}), 7.23(\mathrm{~d}$, $J=8.3 \mathrm{~Hz}, 4 \mathrm{H}), 7.66(\mathrm{~d}, J=5.8 \mathrm{~Hz}, 2 \mathrm{H}), 8.32(\mathrm{~d}, J=5.8 \mathrm{~Hz}, 2 \mathrm{H}), 8.36(\mathrm{~d}, J=7.4 \mathrm{~Hz}, 2 \mathrm{H}) .{ }^{13} \mathrm{C}$ NMR (101 MHz, CD 3 OD) $\delta$ 25.11(2C), 26.80 (2C), 31.60 (2C), 35.79 (2C), 51.49 (2C), 51.70 (2C), $59.04(2 \mathrm{C}), 102.91(2 \mathrm{C}), 118.30(2 \mathrm{C}), 121.77(2 \mathrm{C}), 127.95(4 \mathrm{C}), 129.85(4 \mathrm{C}), 132.79(2 \mathrm{C})$, $136.92(2 \mathrm{C}), 142.60(2 \mathrm{C}), 144.24(2 \mathrm{C}), 146.86(2 \mathrm{C}), 153.06(2 \mathrm{C})$. HRMS-m/z $(\mathrm{M})^{+}$calculated for $\mathrm{C}_{40} \mathrm{H}_{44} \mathrm{~N}_{4} \mathrm{~S}_{2}$ : 644.2996; found: 648.2584.

1,1'-((butane-1,4-diylbis(4,1-phenylene))bis(methylene))bis(4-(pyrrolidin-1-yl)thieno[3,2-d]pyrimidin1-ium) bromide Ff-7. Following the general procedure, after workup as described previously, compound Ff-7 was isolated as a yellow solid. Yield: $19 \%$, mp: $215-217{ }^{\circ} \mathrm{C}$. ${ }^{1} \mathrm{H}$ NMR (400 MHz, CD $3 \mathrm{OD}) \delta 1.62(\mathrm{~s}, 4 \mathrm{H}), 2.13-2.15(\mathrm{~m}, 4 \mathrm{H}), 2.29-2.32(\mathrm{~m}, 4 \mathrm{H}), 2.64(\mathrm{~s}, 4 \mathrm{H})$, 4.01-4.04 (m, 4H), 4.21-4.23 (m, 4H), $5.66(\mathrm{~s}, 4 \mathrm{H}), 7.22(\mathrm{~d}, J=8.0 \mathrm{~Hz}, 4 \mathrm{H}), 7.32(\mathrm{~d}, J=8.0$ $\mathrm{Hz}, 4 \mathrm{H}), 7.62(\mathrm{~d}, J=5.7 \mathrm{~Hz}, 2 \mathrm{H}), 8.46(\mathrm{~d}, J=5.7 \mathrm{~Hz}, 2 \mathrm{H}), 8.88(\mathrm{~s}, 2 \mathrm{H}) .{ }^{13} \mathrm{C} \mathrm{NMR}(101 \mathrm{MHz}$, $\left.\mathrm{CD}_{3} \mathrm{OD}\right) \delta 24.41(2 \mathrm{C}), 26.58(2 \mathrm{C}), 31.37(2 \mathrm{C}), 35.58(2 \mathrm{C}), 50.06(2 \mathrm{C}), 51.02(2 \mathrm{C}), 56.12(2 \mathrm{C})$, $117.56(2 \mathrm{C}), 117.96(2 \mathrm{C}), 127.95$ (4C), 129.73 (4C), 131.85 (2C), $139.41(2 \mathrm{C}), 144.25(2 \mathrm{C}), 146.96$ (2C), 150.55 (2C), 156.05 (2C). HRMS- $m / z(M)^{+}$calculated for $\mathrm{C}_{38} \mathrm{H}_{42} \mathrm{~N}_{6} \mathrm{~S}_{2}$ : 646.2901; found: 646.2936 .

1,1'-((butane-1,4-diylbis(4,1-phenylene))bis(methylene))bis(4-(pyrrolidin-1-yl)thieno[2,3-d]pyrimidin1-ium) bromide Ff-3. Following the general procedure, after workup as described previously, compound Ff-3 was isolated as a grey solid. Yield: $42 \%, \mathrm{mp}: 288-290{ }^{\circ} \mathrm{C} .{ }^{1} \mathrm{H}$ NMR $\left(500 \mathrm{MHz}, \mathrm{CD}_{3} \mathrm{OD}\right) \delta 1.63(\mathrm{~s}, 4 \mathrm{H}), 2.12-2.14(\mathrm{~m}, 4 \mathrm{H}), 2.26-2.28(\mathrm{~m}, 4 \mathrm{H}), 2.66(\mathrm{~s}, 4 \mathrm{H})$, 4.03-4.06 (m, 4H), 4.14-4.17 (m, 4H), $5.62(\mathrm{~s}, 4 \mathrm{H}), 7.25(\mathrm{~d}, J=8.1 \mathrm{~Hz}, 4 \mathrm{H}), 7.37(\mathrm{~d}, J=8.1 \mathrm{~Hz}$, $4 \mathrm{H}), 7.73(\mathrm{~d}, J=5.9 \mathrm{~Hz}, 2 \mathrm{H}), 7.92(\mathrm{~d}, J=6.0 \mathrm{~Hz}, 2 \mathrm{H}), 8.92(\mathrm{~s}, 2 \mathrm{H}) .{ }^{13} \mathrm{C} \mathrm{NMR}(126 \mathrm{MHz}$, $\left.\mathrm{CD}_{3} \mathrm{OD}\right) \delta 24.33(2 \mathrm{C}), 26.78(2 \mathrm{C}), 31.50(2 \mathrm{C}), 35.76(2 \mathrm{C}), 51.22(2 \mathrm{C}), 51.67(2 \mathrm{C}), 58.12(2 \mathrm{C})$, 
118.25 (2C), $123.98(2 \mathrm{C}), 124.17(2 \mathrm{C}), 128.97(4 \mathrm{C}), 129.87(4 \mathrm{C}), 130.22(2 \mathrm{C}), 144.97(2 \mathrm{C}), 149.32$ (2C), 154.40 (2C), 155.42 (2C). HRMS-m/z (M) calculated for $\mathrm{C}_{38} \mathrm{H}_{42} \mathrm{~N}_{6} \mathrm{~S}_{2}$ : 646.2901; found: 646.2930 .

1,1'-((butane-1,4-diylbis(4,1-phenylene))bis(methylene))bis(4-(piperidin-1-yl)thieno[3,2-d]pyrimidin1-ium) bromide $\mathbf{F a}$-33. Following the general procedure, after workup as described previously, compound Fa-33 was isolated as a light-yellow solid. Yield: $89 \%$, mp: $276-278{ }^{\circ} \mathrm{C} .{ }^{1} \mathrm{H}$ NMR $\left(400 \mathrm{MHz}, \mathrm{CD}_{3} \mathrm{OD}\right) \delta 1.57(\mathrm{~m}, 4 \mathrm{H}), 1.82-1.84(\mathrm{~m}, 12 \mathrm{H}), 2.59(\mathrm{t}, J=6.7 \mathrm{~Hz}, 4 \mathrm{H}), 4.21-4.24(\mathrm{~m}$, $8 \mathrm{H}), 5.62(\mathrm{~s}, 4 \mathrm{H}), 7.18(\mathrm{~d}, J=8.2 \mathrm{~Hz}, 4 \mathrm{H}), 7.26(\mathrm{~d}, J=8.2 \mathrm{~Hz}, 4 \mathrm{H}), 7.58(\mathrm{~d}, J=5.8 \mathrm{~Hz}, 2 \mathrm{H})$, $8.39(\mathrm{~d}, J=5.8 \mathrm{~Hz}, 2 \mathrm{H}), 8.84(\mathrm{~s}, 2 \mathrm{H}) .{ }^{13} \mathrm{C} \mathrm{NMR}\left(101 \mathrm{MHz}, \mathrm{CD}_{3} \mathrm{OD}\right) \delta 155.82$ (2C), 149.38 (2C), $147.54(2 \mathrm{C}), 143.51$ (2C), 137.97 (2C), 130.99 (2C), 128.95 (4C), 127.15 (4C), 117.47 (2C), 115.00 (2C), 55.40 (2C), 50.09 (4C), 34.79 (2C), 30.61 (2C), 25.76 (4C), 23.44 (2C). HRMS-m/z $(\mathrm{M})^{+}$calculated for $\mathrm{C}_{40} \mathrm{H}_{46} \mathrm{~N}_{6} \mathrm{~S}_{2}: 674.3225$, found: 674.3190 .

1,1'-((butane-1,4-diylbis(4,1-phenylene))bis(methylene))bis(4-(piperidin-1-yl)thieno[2,3-d]pyrimidin1-ium) bromide $\mathbf{F f}$-6. Following the general procedure, after workup as described previously, compound Ff-6 was isolated as a grey solid. Yield: $11 \%, \mathrm{mp}: 282-284{ }^{\circ} \mathrm{C}$. ${ }^{1} \mathrm{H}$ NMR (400 MHz, CD $\mathrm{CD}_{3} \mathrm{OD} 1.66(\mathrm{~s}, 4 \mathrm{H}), 1.90-1.92(\mathrm{~m}, 12 \mathrm{H}), 2.68(\mathrm{~s}, 4 \mathrm{H}), 4.30-4.32(\mathrm{~m}, 8 \mathrm{H}), 5.63$ $(\mathrm{s}, 4 \mathrm{H}), 7.27(\mathrm{~d}, J=8.0 \mathrm{~Hz}, 4 \mathrm{H}), 7.40(\mathrm{~d}, J=8.5 \mathrm{~Hz}, 4 \mathrm{H}), 7.78(\mathrm{~d}, J=5.8 \mathrm{~Hz}, 2 \mathrm{H}), 7.84(\mathrm{~d}$, $J=6.2 \mathrm{~Hz}, 2 \mathrm{H}), 8.91$ (s, 2H). ${ }^{13} \mathrm{C}$ NMR (126 MHz, CD $\left.3 \mathrm{OD}\right) \delta 24.23(4 \mathrm{C}), 26.39(2 \mathrm{C}), 31.44$ (2C), $35.70(2 \mathrm{C}), 51.05(4 \mathrm{C}), 58.06(2 \mathrm{C}), 117.08(2 \mathrm{C}), 123.81(2 \mathrm{C}), 124.42(2 \mathrm{C}), 128.97(4 \mathrm{C})$, 129.82 (4C), 130.89 (2C), 144.92 (2C), 148.92 (2C), 155.67 (2C), $156.82(2 \mathrm{C})$. HRMS-m/z (M) ${ }^{+}$ calculated for $\mathrm{C}_{40} \mathrm{H}_{46} \mathrm{~N}_{6} \mathrm{~S}_{2}: 674.3225$, found: 674.3239 .

(1,1'((butane1,4diylbis(4,1phenylene))bis(methylene))bis(4-(azepan-1-yl)thieno[3,2-d]pyrimidin-1ium)) bromide $\mathbf{F a}$-29. Following the general procedure, after workup as described previously, compound Fa-29 was isolated as a light-brown solid. Yield: $40 \%$, mp: $268-270{ }^{\circ} \mathrm{C}$. ${ }^{1} \mathrm{H}$ NMR (500 MHz, CD 3 OD) $\delta 1.59-1.61(\mathrm{~m}, 4 \mathrm{H}), 1.69-1.71(\mathrm{~m}, 8 \mathrm{H}), 1.96-1.98(\mathrm{~m}, 4 \mathrm{H}), 2.04-2.06$ $(\mathrm{m}, 4 \mathrm{H}), 2.62(\mathrm{t}, J=6.9 \mathrm{~Hz}, 4 \mathrm{H}), 4.20-4.22(\mathrm{~m}, 4 \mathrm{H}), 4.24-4.26(\mathrm{~m}, 4 \mathrm{H}), 5.65(\mathrm{~s}, 4 \mathrm{H}), 7.21(\mathrm{~d}$, $J=7.9 \mathrm{~Hz}, 4 \mathrm{H}), 7.30(\mathrm{~d}, J=7.9 \mathrm{~Hz}, 4 \mathrm{H}), 7.61(\mathrm{~d}, J=5.8 \mathrm{~Hz}, 2 \mathrm{H}), 8.45(\mathrm{~d}, J=5.7 \mathrm{~Hz}, 2 \mathrm{H})$, 8.87 (s, 2H). ${ }^{13} \mathrm{C}$ NMR (126 MHz, CD $\left.\mathrm{OD}\right) \delta 26.09$ (2C), 26.20 (2C), 26.31 (2C), 28.11 (2C), 30.65 (2C), 34.83 (2C), 50.30 (2C), 51.32 (2C), 55.45 (2C), $115.25(2 \mathrm{C}), 117.31(2 \mathrm{C}), 127.22$ (4C), 128.99 (4C), 130.97 (2C), 138.63 (2C), 143.55 (2C), 147.08 (2C), 149.32 (2C), 157.10 (2C). HRMS- $m / z(\mathrm{M})^{+}$calculated for $\mathrm{C}_{42} \mathrm{H}_{50} \mathrm{~N}_{6} \mathrm{~S}_{2}$ : 702.3538, found: 702.3601 .

(1,1'((butane1,4diylbis(4,1phenylene))bis(methylene))bis(4-(azepan-1-yl)thieno[2,3-d]pyrimidin1-ium)) bromide $\mathbf{F f}$-35. Following the general procedure, after workup as described previously, compound Ff-35 was isolated as a brown solid. Yield: $34 \%$, mp: $117-119{ }^{\circ} \mathrm{C}$. ${ }^{1} \mathrm{H}$ NMR (500 MHz, CD 3 OD) $\delta 1.64(\mathrm{~s}, 4 \mathrm{H}), 1.71-1.73(\mathrm{~m}, 8 \mathrm{H}), 1.91-1.93(\mathrm{~m}, 4 \mathrm{H}), 2.06-2.08$ $(\mathrm{m}, 4 \mathrm{H}), 2.66(\mathrm{~s}, 4 \mathrm{H}), 4.18-4.20(\mathrm{~m}, 4 \mathrm{H}), 4.22-4.24(\mathrm{~m}, 4 \mathrm{H}), 5.64(\mathrm{~s}, 4 \mathrm{H}), 7.26(\mathrm{~d}, J=8.2 \mathrm{~Hz}$, $4 \mathrm{H}), 7.40(\mathrm{~d}, J=8.1 \mathrm{~Hz}, 4 \mathrm{H}), 7.77(\mathrm{~d}, J=6.0 \mathrm{~Hz}, 2 \mathrm{H}), 7.85(\mathrm{~d}, J=6.0 \mathrm{~Hz}, 2 \mathrm{H}), 8.94(\mathrm{~s}$, 2H). ${ }^{13} \mathrm{C} \mathrm{NMR}\left(126 \mathrm{MHz}, \mathrm{CD}_{3} \mathrm{OD}\right) \delta 27.39$ (4C), 28.29 (4C), 31.49 (2C), 35.76 (2C), 51.22 (2C), 52.47 (2C), $58.18(2 \mathrm{C}), 117.27(2 \mathrm{C}), 124.25$ (2C), 124.53 (2C), $129.05(4 \mathrm{C}), 129.89(4 \mathrm{C})$, 130.12 (2C), 144.98 (2C), 148.84 (2C), 155.47 (2C), 157.52 (2C). HRMS-m/z (M) ${ }^{+}$calculated for $\mathrm{C}_{42} \mathrm{H}_{50} \mathrm{~N}_{6} \mathrm{~S}_{2}$ : 702.3538, found: 702.3527 .

4,4'-(((ethane-1,2-diylbis(oxy))bis(4,1-phenylene))bis(methylene))bis(7-(pyrrolidin-1-yl) thieno[3,2-b]pyridin-4-ium) bromide Ff-2. Following the general procedure, after workup as described previously, compound Ff-2 was isolated as a brown solid. Yield: $21 \%, \mathrm{mp}$ : 280-282 ${ }^{\circ} \mathrm{C} .{ }^{1} \mathrm{H}$ NMR (400 MHz, CD $\left.3 \mathrm{OD}\right) \delta 2.19-2.21(\mathrm{~m}, 8 \mathrm{H}), 3.74-3.76(\mathrm{~m}, 4 \mathrm{H}), 4.30-4.32$ $(\mathrm{m}, 8 \mathrm{H}), 5.63(\mathrm{~s}, 4 \mathrm{H}), 6.74(\mathrm{~d}, J=7.4 \mathrm{~Hz}, 2 \mathrm{H}), 6.99(\mathrm{~d}, J=8.8 \mathrm{~Hz}, 4 \mathrm{H}), 7.29(\mathrm{~d}, \mathrm{~J}=8.8 \mathrm{~Hz}, 4 \mathrm{H})$, $7.69(\mathrm{~d}, J=5.8 \mathrm{~Hz}, 2 \mathrm{H}), 8.32(\mathrm{~d}, J=5.7 \mathrm{~Hz} 2 \mathrm{H}), 8.33(\mathrm{~d}, J=7.5 \mathrm{~Hz}, 2 \mathrm{H}) .{ }^{13} \mathrm{C} \mathrm{NMR}(101 \mathrm{MHz}$, $\left.\mathrm{CD}_{3} \mathrm{OD}\right) \delta 24.12(2 \mathrm{C}), 25.79(2 \mathrm{C}), 50.65(4 \mathrm{C}), 57.77(2 \mathrm{C}), 66.50(2 \mathrm{C}), 101.85(2 \mathrm{C}), 114.86(4 \mathrm{C})$, $117.26(2 \mathrm{C}), 120.79(2 \mathrm{C}), 126.59$ (2C), 128.60 (4C), $135.86(2 \mathrm{C}), 141.38(2 \mathrm{C}), 145.84(2 \mathrm{C}), 152.02$ (2C), 159.15 (2C). HRMS-m/z (M) calculated for $\mathrm{C}_{38} \mathrm{H}_{40} \mathrm{~N}_{4} \mathrm{O}_{2} \mathrm{~S}_{2}$ : 648.2582, found: 648.2584.

1,1'-(((ethane-1,2-diylbis(oxy))bis(4,1-phenylene))bis(methylene))bis(4-(pyrrolidin-1-yl) thieno[3,2-d]pyrimidin-1-ium) bromide Ff-8. Following the general procedure, after workup as described previously, compound Ff-8 was isolated as a white solid. Yield: 32\%, mp: $217-219^{\circ} \mathrm{C} .{ }^{1} \mathrm{H}$ NMR (500 MHz, CD $\left.3 \mathrm{OD}\right) \delta 2.13-2.15$ (m, 4H). 2.28-2.30 (m, 4H), 
4.01-4.03 (m, 4H), 4.22-4.24 (m, 4H), $4.33(\mathrm{~s}, 4 \mathrm{H}), 5.62(\mathrm{~s}, 4 \mathrm{H}), 7.02(\mathrm{~d}, J=8.7 \mathrm{~Hz}, 4 \mathrm{H}), 7.38$ $(\mathrm{d}, J=8.6 \mathrm{~Hz}, 4 \mathrm{H}), 7.66(\mathrm{~d}, J=5.7 \mathrm{~Hz}, 2 \mathrm{H}), 8.47(\mathrm{~d}, J=5.7 \mathrm{~Hz}, 2 \mathrm{H}), 8.86(\mathrm{~s}, 2 \mathrm{H}) .{ }^{13} \mathrm{C} \mathrm{NMR}$ ( $\left.126 \mathrm{MHz}, \mathrm{CD}_{3} \mathrm{OD}\right) \delta 24.53$ (2C), 26.70 (2C), 50.17 (2C), 51.13 (2C), 56.05 (2C), $67.44(2 \mathrm{C})$, $115.92(4 \mathrm{C}), 117.70(2 \mathrm{C}), 118.08(2 \mathrm{C}), 126.76(2 \mathrm{C}), 129.81(4 \mathrm{C}), 139.56(2 \mathrm{C}), 147.07$ (2C), 150.55 (2C), 156.18 (2C), 160.20 (2C). HRMS-m/z (M) ${ }^{+}$calculated for $\mathrm{C}_{36} \mathrm{H}_{38} \mathrm{~N}_{6} \mathrm{O}_{2} \mathrm{~S}_{2}$ : 650.2487, found: 650.2497 .

1,1'-(((ethane-1,2-diylbis(oxy))bis(4,1-phenylene))bis(methylene))bis(4-(pyrrolidin-1-yl) thieno[2,3-d]pyrimidin-1-ium) bromide Ff-4. Following the general procedure, after workup as described previously, compound Ff-4 was isolated as a brown solid. Yield: 42\%, mp: $193-195{ }^{\circ} \mathrm{C} .{ }^{1} \mathrm{H}$ NMR (500 MHz, CD 3 OD) $\delta 2.12-2.14$ (m, 4H). 2.26-2.28 (m, 4H), 4.03-4.05 (m, 4H), 4.15-4.17 (m, 4H), $4.36(\mathrm{~s}, 4 \mathrm{H}), 5.60(\mathrm{~s}, 4 \mathrm{H}), 7.05(\mathrm{~d}, J=8.8 \mathrm{~Hz}, 4 \mathrm{H}), 7.45$ $(\mathrm{d}, J=8.8 \mathrm{~Hz}, 4 \mathrm{H}), 7.75(\mathrm{~d}, J=5.9 \mathrm{~Hz}, 2 \mathrm{H}), 7.93(\mathrm{~d}, J=5.9 \mathrm{~Hz}, 2 \mathrm{H}), 8.92(\mathrm{~s}, 2 \mathrm{H}) .{ }^{13} \mathrm{C} \mathrm{NMR}$ (126 MHz, CD $3 \mathrm{OD}) \delta 24.50$ (2C), 26.95 (2C), 50.12 (2C), 50.86 (2C), 58.12 (2C), 67.63 (2C), 116.02 (4C), 118.43 (2C), 124.10 (2C), 124.40 (2C), 125.12 (2C), $130.90(4 \mathrm{C}), 149.38(2 \mathrm{C}), 154.48$ (2C), 155.49 (2C), 160.76 (2C). HRMS-m/z (M) ${ }^{+}$calculated for $\mathrm{C}_{36} \mathrm{H}_{38} \mathrm{~N}_{6} \mathrm{O}_{2} \mathrm{~S}_{2}$ : 650.2487, found: 650.2514 .

1,1'-(((ethane-1,2-diylbis(oxy))bis(4,1-phenylene))bis(methylene))bis(4-(piperidin-1-yl) thieno[3,2-d]pyrimidin-1-ium) bromide Ff-28. Following the general procedure, after workup as described previously, compound Ff-28 was isolated as a grey solid. Yield: 25\%, mp: 198-200 ${ }^{\circ} \mathrm{C} .{ }^{1} \mathrm{H}$ NMR (400 MHz, DMSO) $\delta$ 1.76-178-(m, 12H), 4.15-4.17 (m, 8H), 4.28 $(\mathrm{s}, 4 \mathrm{H}), 5.66(\mathrm{~s}, 4 \mathrm{H}), 6.99(\mathrm{~d}, J=8.6 \mathrm{~Hz}, 4 \mathrm{H}), 7.44(\mathrm{~d}, J=8.5 \mathrm{~Hz}, 4 \mathrm{H}), 7.80(\mathrm{~d}, J=5.7 \mathrm{~Hz}$, $2 \mathrm{H}), 8.65(\mathrm{~d}, \mathrm{~J}=5.7 \mathrm{~Hz}, 2 \mathrm{H}), 9.17(\mathrm{~s}, 2 \mathrm{H}) .{ }^{13} \mathrm{C} \mathrm{NMR}(101 \mathrm{MHz}, \mathrm{DMSO}) \delta 23.22(2 \mathrm{C}), 25.94$ (4C), 49.60 (4C), 54.51 (2C), 66.31 (2C), 114.58 (4C), $114.83(2 \mathrm{C}), 117.95(2 \mathrm{C}), 126.44(2 \mathrm{C})$, 129.35 (4C), 139.02 (2C), $147.11(2 \mathrm{C}), 149.84(2 \mathrm{C}), 155.36(2 \mathrm{C}), 158.40(2 \mathrm{C}) . \mathrm{HRMS}-\mathrm{m} / z(\mathrm{M})^{+}$ calculated for $\mathrm{C}_{38} \mathrm{H}_{42} \mathrm{~N}_{6} \mathrm{O}_{2} \mathrm{~S}_{2}: 678.2800$, found: 678.2774 .

$1,1^{\prime}$-(((ethane-1,2-diylbis(oxy))bis(4,1-phenylene))bis(methylene))bis(4-(piperidin-1-yl) thieno[2,3-d]pyrimidin-1-ium) bromide Ff-5. Following the general procedure, after workup as described previously, compound Ff-5 was isolated as a brown solid. Yield: $41 \%$, mp: $>280{ }^{\circ} \mathrm{C} .{ }^{1} \mathrm{H}$ NMR $\left(500 \mathrm{MHz}, \mathrm{CD}_{3} \mathrm{OD}\right) \delta 1.89(\mathrm{~m}, 12 \mathrm{H}), 4.25(\mathrm{~m}, 8 \mathrm{H}), 4.36(\mathrm{~s}, 4 \mathrm{H})$, $5.60(\mathrm{~s}, 4 \mathrm{H}), 7.06(\mathrm{~d}, J=8.8 \mathrm{~Hz}, 4 \mathrm{H}), 7.46(\mathrm{~d}, \mathrm{~J}=8.8 \mathrm{~Hz}, 4 \mathrm{H}), 7.78(\mathrm{~d}, J=6.0 \mathrm{~Hz}, 2 \mathrm{H}), 7.83(\mathrm{~d}$, $J=6.0 \mathrm{~Hz}, 2 \mathrm{H}), 8.89$ (s, 2H). ${ }^{13} \mathrm{C}$ NMR $\left(126 \mathrm{MHz}, \mathrm{CD}_{3} \mathrm{OD}\right) \delta 24.29(2 \mathrm{C}), 26.56(4 \mathrm{C}), 51.06$ (4C), $57.95(2 \mathrm{C}), 67.46(2 \mathrm{C}), 115.86(4 \mathrm{C}), 117.16(2 \mathrm{C}), 123.82(2 \mathrm{C}), 124.54(2 \mathrm{C}), 124.92(2 \mathrm{C})$, 130.79 (4C), $148.86(2 \mathrm{C}), 155.65(2 \mathrm{C}), 156.90(2 \mathrm{C}), 160.61(2 \mathrm{C})$. HRMS-m/z $(\mathrm{M})^{+}$calculated for $\mathrm{C}_{38} \mathrm{H}_{42} \mathrm{~N}_{6} \mathrm{O}_{2} \mathrm{~S}_{2}$ : 678.2811, found: 678.2839 .

1,1'-(((ethane-1,2-diylbis(oxy))bis(4,1-phenylene))bis(methylene))bis(4-(azepan-1-yl) thieno[3,2-d]pyrimidin-1-ium) bromide Ff-34. Following the general procedure, after workup as described previously, compound Ff-34 was isolated as a brown solid. Yield: 45\%, mp: $201-202{ }^{\circ} \mathrm{C} .{ }^{1} \mathrm{H}$ NMR (500 MHz, CD $\left.\mathrm{OD}\right) \delta 1.71-1.73(\mathrm{~m}, 4 \mathrm{H}), 1.92-1.94(\mathrm{~m}$, $4 \mathrm{H}), 2.08-2.10(\mathrm{~m}, 8 \mathrm{H}), 4.22-4.24(\mathrm{~m}, 4 \mathrm{H}), 4.25-4.27(\mathrm{~m}, 4 \mathrm{H}), 4.33(\mathrm{~s}, 4 \mathrm{H}), 5.64(\mathrm{~s}, 4 \mathrm{H}), 7.03$ $(\mathrm{d}, J=8.8 \mathrm{~Hz}, 4 \mathrm{H}), 7.39(\mathrm{~d}, J=8.7 \mathrm{~Hz}, 4 \mathrm{H}), 7.67(\mathrm{~d}, J=5.8 \mathrm{~Hz}, 2 \mathrm{H}), 8.48(\mathrm{~d}, J=5.8 \mathrm{~Hz}$, 2H), 8.87 (s, 2H). ${ }^{13} \mathrm{C} \mathrm{NMR}\left(126 \mathrm{MHz}, \mathrm{CD}_{3} \mathrm{OD}\right) \delta 27.22$ (4C), 29.02 (4C), 51.21 (2C), 52.22 (2C), 56.15 (2C), 67.45 (2C), 115.90 (4C), 116.16 (2C), 118.21 (2C), $126.68(2 \mathrm{C}), 129.82(4 \mathrm{C})$, $139.51(2 \mathrm{C}), 147.97(2 \mathrm{C}), 150.11(2 \mathrm{C}), 158.01(2 \mathrm{C}), 160.26(2 \mathrm{C})$. HRMS- $m / z(\mathrm{M})^{+}$calculated for $\mathrm{C}_{40} \mathrm{H}_{46} \mathrm{~N}_{6} \mathrm{O}_{2} \mathrm{~S}_{2}: 706.3124$, found: 706.3068 .

1,1'-(((ethane-1,2-diylbis(oxy))bis(4,1-phenylene))bis(methylene))bis(4-(azepan-1-yl) thieno[3,2-d]pyrimidin-1-ium) bromide Ff-36. Following the general procedure, after workup as described previously, compound Ff-36 was isolated as a brown solid. Yield: 27\%, mp: $205-207{ }^{\circ} \mathrm{C} .{ }^{1} \mathrm{H}$ NMR (400 MHz, CD 3 OD) $\delta 1.72-1.73(\mathrm{~m}, 8 \mathrm{H}), 2.00-2.03(\mathrm{~m}$, $4 \mathrm{H}), 2.04-2.06(\mathrm{~m}, 4 \mathrm{H}), 4.19-4.22(\mathrm{~m}, 4 \mathrm{H}), 4.22-4.24(\mathrm{~m}, 4 \mathrm{H}), 4.37(\mathrm{~s}, 4 \mathrm{H}), 5.61(\mathrm{~s}, 4 \mathrm{H}), 7.07$ $(\mathrm{d}, J=8.7 \mathrm{~Hz}, 4 \mathrm{H}), 7.47(\mathrm{~d}, J=8.7 \mathrm{~Hz}, 4 \mathrm{H}), 7.78(\mathrm{~d}, J=6.0 \mathrm{~Hz}, 2 \mathrm{H}), 7.85(\mathrm{~d}, J=6.0 \mathrm{~Hz}$, 2H), 8.91 (s, 2H). ${ }^{13} \mathrm{C}$ NMR (101 MHz, DMSO) $\delta 26.31$ (4C), 27.00 (4C), $49.82(2 \mathrm{C}), 51.23$ (2C), $56.51(2 \mathrm{C}), 66.35(2 \mathrm{C}), 114.84(4 \mathrm{C}), 116.08(2 \mathrm{C}), 123.83(2 \mathrm{C}), 124.35(2 \mathrm{C}), 124.45$ (2C), 130.11 (4C), 148.46 (2C), 153.91 (2C), 156.10 (2C), 158.73 (2C). HRMS-m/z (M) calculated for $\mathrm{C}_{40} \mathrm{H}_{46} \mathrm{~N}_{6} \mathrm{O}_{2} \mathrm{~S}_{2}$ : 706.3124, found: 706.3183 . 


\subsection{Biological Activity}

Table 2 summarizes the effect of the final compounds in infected erythrocytes. In general, all compounds show nanomolar activity, the most active compound being Ff- 4 $(11.5 \mathrm{nM})$. In terms of structure, there seems to be no difference between monocationic and bis-cationic compounds regarding their antimalarial activity. Among the monocationic compounds, Fa-M3 (isomer thieno[2,3-d]pyrimidin) stands out, but the rest of the isomers follow up very closely, and the difference in the activity is not considered to be remarkable.

Table 2. In vitro inhibitory effects of final compounds.

\begin{tabular}{|c|c|c|c|}
\hline Compounds & $\mathrm{IC}_{50}{ }^{\mathrm{a}}$ & $\begin{array}{l}\text { PfCK Fractional } \\
\text { Activity at } 25 \mu \mathrm{M}\end{array}$ & $\mathrm{IC}_{50} \operatorname{PfCK^{\mathrm {b}}}$ \\
\hline Fa-M2 & 0.0489 & $100.75 \pm 13.73$ & \\
\hline Fa-M1 & 0.0410 & $54.65 \pm 11.69$ & \\
\hline Fa-M3 & 0.0351 & $96.91 \pm 18.68$ & \\
\hline Fg-9 & 0.1659 & nd & \\
\hline Fa-21 & 0.0137 & nd & \\
\hline Fg-14 & 0.0206 & nd & \\
\hline Fa-24 & 0.0578 & $57.08 \pm 5.15$ & \\
\hline Fg-30 & 0.0279 & $54.77 \pm 7.20$ & \\
\hline Fg-10 & 0.0530 & $44.66 \pm 8.55$ & \\
\hline Fa-22 & 0.0514 & $57.03 \pm 5.37$ & $11.70 \pm 0.49$ \\
\hline Fg-18 & 0.0604 & $49.53 \pm 8.06$ & $11.09 \pm 1.00$ \\
\hline Fp-1 & 0.1422 & $12.88 \pm 3.32$ & $7.27 \pm 0.23$ \\
\hline Fp-8 & 0.2816 & $8.10 \pm 5.80$ & $4.17 \pm 0.48$ \\
\hline Fg-12 & 0.3049 & nd & \\
\hline Fg-17 & 0.2273 & $50.28 \pm 7.88$ & \\
\hline Fg-13 & 0.1429 & $99.13 \pm 12.01$ & \\
\hline Fa-27 & 0.1205 & $82.64 \pm 4.90$ & \\
\hline Fg-32 & $>0.25$ & $83.85 \pm 9.53$ & \\
\hline Fa-26 & 0.2093 & $78.02 \pm 8.13$ & \\
\hline Fg-20 & 0.0976 & $96.62 \pm 13.12$ & \\
\hline Fg-11 & 0.2321 & $32.96 \pm 1.48$ & $16.46 \pm 1.43$ \\
\hline Fg-16 & 0.0206 & $79.74 \pm 10.35$ & $26.53 \pm 2.44$ \\
\hline Fg-15 & 0.0127 & $97.48 \pm 9.22$ & \\
\hline Fa-25 & 0.0347 & nd & \\
\hline Fg-31 & 0.0347 & $87.41 \pm 2.20$ & \\
\hline Fa-23 & 0.0678 & nd & \\
\hline Fg-19 & 0.0715 & nd & \\
\hline Ff-1 & 0.0901 & $47.03 \pm 3.53$ & $10.90 \pm 1.33$ \\
\hline Ff-7 & 0.0219 & $55.02 \pm 4.07$ & $13.32 \pm 3.82$ \\
\hline Ff-3 & 0.0388 & nd & \\
\hline Fa-33 & 0.0439 & $68.76 \pm 6.03$ & \\
\hline Ff-6 & nd & nd & \\
\hline Fa-29 & 0.0556 & $46.72 \pm 9.49$ & $4.64 \pm 0.20$ \\
\hline Ff-35 & 0.0484 & $57.62 \pm 12.29$ & \\
\hline Ff-2 & 0.0740 & $81.77 \pm 3.93$ & \\
\hline Ff-8 & 0.0352 & $63.06 \pm 6.74$ & \\
\hline Ff-4 & 0.0115 & $90.72 \pm 4.57$ & $37.36 \pm 3.24$ \\
\hline Fa-28 & 0.0471 & $84.39 \pm 7.53$ & \\
\hline Ff-5 & 0.0224 & $91.06 \pm 4.27$ & \\
\hline Ff-34 & 0.0879 & $52.17 \pm 12.43$ & \\
\hline Ff-36 & 0.1861 & $46.39 \pm 12.44$ & \\
\hline
\end{tabular}


Table 2. Cont.

\begin{tabular}{|c|c|c|c|}
\hline Compounds & $\mathrm{IC}_{50}{ }^{\mathrm{a}}$ & $\begin{array}{l}\text { PfCK Fractional } \\
\text { Activity at } 25 \mu \mathrm{M}\end{array}$ & $\mathrm{IC}_{50} P f \mathrm{CK}^{\mathrm{b}}$ \\
\hline \multicolumn{4}{|c|}{ Reference Compounds ${ }^{c}$} \\
\hline HC-3 & $>50$ & & 250 \\
\hline MN58b & 0.0035 & & 106 \\
\hline RSM-932A & 0.0265 & & 1.75 \\
\hline BR-23 & $0.003 \pm 0.0002$ & & 276 \\
\hline BR-25 & $0.002 \pm 0.0003$ & & 103 \\
\hline BR-31 & $0.007 \pm 0.0006$ & & \\
\hline BR-33 & $0.045 \pm 0.003$ & & \\
\hline $10 a$ & $0.016 \pm 0.001$ & & $>\geq 100$ \\
\hline $10 \mathrm{k}$ & $0.035 \pm 0.004$ & & $10.949 \pm 0.124$ \\
\hline Chloroquine & $0.015 \pm 0.2709$ & & \\
\hline
\end{tabular}

${ }^{\mathrm{a}}$ In vitro IC50 values against P. falciparum $(\mu \mathrm{M}) .{ }^{\mathrm{b}}$ IC50 $=$ Compound concentration required to inhibit $P f C K$ enzyme by $50 \%(\mu \mathrm{M})$. nd: not determined. ${ }^{c}$ Data from Refs. $[7,8,10]$.

With respect to the biscationic compounds and considering the 5 types of linker used, it can be observed that when the spacer is bipyridinyl (Fg-12, Fg-17, Fg-13, Fa-27, Fg-32, Fa-26 and Fg-20) there is a notable decrease in the activity with respect to their biphenylic counterparts (Fg-9, Fa-21, Fg-14, Fa-24, Fg-30, Fg-10, Fa-22, Fg-18, Fp-1 and Fp-8). This difference is more pronounced when the volume of the 4-substituent in the cationic head increases (Fa-22 and Fg-18 vs Fa-26 and Fg-20). Conversely, when the substituent is pyrrolidine there is hardly any difference, except for Fg-13 and Fg-17 vs Fg-14 and Fa-21, where there is more than a 10-fold difference in activity.

The remaining biphenyl and bibenzyl, biphenethyl and 1,2-diphenoxyethane linkers feature very similar values. Starting with the biphenyl spacer, the substituent at 4 has a visible influence, with pyrrolidine again giving the best results (see Table 2 Fa-21, Fg-14, Ff-15 and Ff-4), the increased volume of this cycloalkylamine from piperidine to azepane gradually decreases the activity. However, it can be considered one of the best families, as there is hardly any difference between the least active $\mathbf{F g}-\mathbf{1 8}\left(\mathrm{IC}_{50}=60 \mathrm{nM}\right)$ and the most active $\mathbf{F f}-21\left(\mathrm{IC}_{50}=13.7 \mathrm{nM}\right)$. It is worth noting that in this family two thieno pyrimidine isomers Fp-1 and Fp-8 substituted at 4 by an $N$-methyl-aniline and $p$-Chloro- $N$-methylaniline were also synthesized and evaluated in order to compare the results with those where the substituent is a cycloalkylamine. Nonetheless, a drastic decrease in activity was observed. Finally, the thienopyrimidin isomers stand out against the thienopyridin isomers, suggesting that the introduction of a second $N$ atom in the cationic head is highly beneficial.

Continuing the SAR analysis, a very similar pattern emerges. Both when the linkers are bibenzyl and biphenethyl, the thieno[2,3-d] pyrimidine isomers stand out against thieno[3,2-d]pyridine in both. See compounds Fg-15 and Fg-31 belongs to the bibenzyl family and Ff-3 and Ff-35 with biphenethylic spacer. The volume of the pyrrolidine ring is postulated to be the best, even though the differences are not too great.

The 1,2-diphenoxyethane derivatives behave similarly and the introduction of 2 oxygen atoms between the aromatic rings does not seem to affect their activity. In comparison to the reference compounds $10 \mathrm{a}$ and $\mathbf{1 0 k}$, which were previously described by our group [8], it can be observed that the homologous compounds Ff- $\mathbf{4}$ and $\mathbf{F f}-5$ feature an improved activity. Both of them belong to the series of bioisosteres derived from thieno[2,3d]pyrimidin-1-ium, with a pyrrolidine or a piperidine group in position 4, respectively. In the consecutive isomers with azepane $\mathbf{F f}-\mathbf{3 4}$ and $\mathbf{F f - 3 6}$ (similar 10k with quinoline), the activity decreases until, rather unexpectedly, Ff-36 (thieno[2,3-d]pyrimidin-1-ium), which features 6 times less activity than 10k.

All final compounds were analyzed as $P f C K$ inhibitors (Table 2), and those with a small residual activity had their $\mathrm{IC}_{50}$ values calculated. The values obtained show, at first sight, two striking features; the first is that the monocationic compounds, despite their 
potent antimalarial activity, do not inhibit the choline kinase activity of the enzyme. The second is that the bipyridinic linker derivatives' (with moderate antimalarial values) are not inhibitors of $P f C K$.

Starting with the biphenyl linker derivatives, compounds Fp-1 and Fp-8 feature the most remarkable $\mathrm{IC}_{50}$ values $(7.27 \pm 0.23$ and $4.17 \pm 0.48 \mu \mathrm{M}$ respectively). Interestingly, these two thienopyrimidine isomers have $\mathrm{N}$-methyl-aniline and $p$-Chloro- $\mathrm{N}$-methyl aniline as substituents at the 4-position of the heterocycle. Therefore these compounds can be considered as bioisosters of compound RMS932A which had an $\mathrm{IC}_{50}$ of $1.75 \mu \mathrm{M}$ and where the 7-quinoline ring is replaced by the two thienopyrimidine isomers. The antimalarial activity has also decreased up to 10-fold with respect to RSM932A: from $0.0265 \mu \mathrm{M}$ to $0.1422 \mu \mathrm{M}$ for Fp-1 and $0.2816 \mu \mathrm{M}$ for Fp-8. This result points out that the bioisosteric change has not favoured the inhibition or antimalarial activity. However, it appears that there is a direct correlation between both activities suggesting that these compounds may display a similar mechanism of action to the RMS932A, i.e., the antimalarial activity is directly related to the inhibition of the enzyme when the substrate is choline, and hence, the $P f C K$ shows activity towards choline kinase and not ethanolamine kinase. The differences in enzyme activity are lower than those in antimalarial activity, and this could be due to the decreased lipophilicity of these new compounds: Fp-1 $(\operatorname{cog} P=3.413)$ and Fp-8 ( $\log \mathrm{P}=4.44)$ while for RSM-923A is (cLogP $=7.44)$. In this same family, however, it is observed that when the substituents in 4 are cycloalkylamines, for example Fa-22 and Fg-18, the $\mathrm{IC}_{50}$ of the enzyme activity reaches moderate values of $11 \mu \mathrm{M}$, while the antimalarial activity is $0.0514 \mu \mathrm{M}$ and $0.0604 \mu \mathrm{M}$, respectively; hence, an alternative and complementary mechanism could be involved. Only a moderate increase in enzymatic activity seems to be observed when the isomer is thieno[3,2-d]pyrimidine with respect to the other isomer, which has the sulphur closer to the positive charge of the cationic heads.

In comparison with biphenyl family, the introduction of 2 carbon atoms between the aromatic rings (the bibenzyl family), exerts a negative effect on the enzyme inhibition, Fg-11 and Fg-16 being the most active compounds of the bibenzyl family with modest $\mathrm{IC}_{50}$ values. In addition, compound $\mathbf{F g}-\mathbf{1 6}$ was found to be one of the most lethal against the parasite regarding this family, suggesting that the inhibition of the enzyme is at least partially involved for this compound. The addition of 2 more carbon atoms (Ff-1, Ff-7, Ff-3, Fa-33, Ff-6, Fa-29 and Ff-35) produces a significant increase in enzyme activity, which is also partially reflected in the notable improvement of the antimalarial activity.

Among these two families, the most active compound is Fa-29, with an $\mathrm{IC}_{50}=4.64 \pm 0.20 \mu \mathrm{M}$. It is a derivative of thieno[3,2-d]pyrimidin-1-ium with an azepanyl group as substituent and biphenethyl as a linker and shows an antimalarial activity of $55.6 \mathrm{nM}$, which is not the best value but exhibits a direct correlation with the inhibition values.

It is worth noting that the asymmetrical reference compounds BR-23 and BR-25, with excellent antimalarial values, can be considered bioisosters of the compounds described in this work: Fg-9, Fa-21, Fg-14 for BR-23 and Ff-1, Ff-7 and Ff-3 for BR-25. A 10-fold decrease in antimalarial activity is observed with respect to the reference compounds, but it is nevertheless striking that the synthesized bioisosters do possess enzymatic activity when the substrate is choline, in contrast to BR-23 and BR-25, which only had inhibitory activity when the enzyme-substrate was ethanolamine.

The BR-31 derivative can also be considered homologous to the compounds Fp-1 and Fp-8, where a 10-fold decrease in parasite lethality has occurred and, also in this case, this could be related to the lack of lipophilicity of the newly synthesized compounds since the enzymatic inhibition values of $\mathbf{F p - 1}$ and $\mathbf{F p}-\mathbf{8}$ are quite considerable.

Analyzing the compounds with the linker 1,2-diphenoxyethane homologous to the compounds already reported [8,27], it can be observed that compounds Ff-34 and Ff-36 show the lowest residual enzyme activity with values of $52.17 \% \pm 12.43$ and $46.39 \% \pm 12.44$, which are precisely the homologues of compound 10k with quinoline and azepane as a substituent in position 4 . However, there is a difference with respect to enzyme activity, since for compound 10a, the mechanism of action must be different as no inhibition of the 
enzyme in its choline kinase or ethanolamine kinase activity is observed. In contrast, when the head is quinolinium and carries an azepane group in position 4 (10k), values are similar to those presented in this work.

Unfortunately, Fa-M2, Fa-M1 and Fa-M3 showed severe aggregation even at $5 \mathrm{mM}$ concentration. As a result, it was difficult to measure their exact concentration, which is crucial for enzymatic assays.

\section{Conclusions}

The bioisosteric changes introduced in the compounds presented in this work have led to antimalarial compounds whose potency is in the nanomolar range. Albeit not as potent as some of the previously published compounds, these inhibitors show a remarkable uniformity in terms of antimalarial activity. Among all the compounds, those with the thieno[2,3-d]pyrimidine isomer and a pyrrolidine at position 4 of the cationic head Fg-15 and Ff-4 stand out, featuring an antimalarial potency of approximately 11 nanomolar. With respect to the spacers, there does not seem to be much influence on the antimalarial activity.

In a first biological approach, the inhibition of the CK enzyme when the substrate used is choline is postulated as one of the mechanisms of action. Further studies could determine if the mechanism of action of these compounds is also related to inhibition of other enzymes involved in the metabolism of PC, such as PfCCT and PfCEPT, which have been validated as antimalarial targets; or to perturbations of choline transport.

In essence, the compounds presented herein can be considered as excellent candidates for further studies since the bioisosteric changes introduced have increased their solubility and therefore their bioavailability while maintaining almost unchanged their antimalarial activity relative to their homologues.

Supplementary Materials: The following are available online at https: / www.mdpi.com/article/ 10.3390 / pharmaceutics13111842/s1, Figure S1. PfCKIC 50 Curves Inhibition of PfCK. Figure S2. IC50Curves. Figure S3. Spectra.

Author Contributions: Conceptualization and methodology L.C.L.-C. and E.P.; writing-original draft preparation L.C.L.-C., E.P. and D.G.-P. Investigation and formal analysis of PfCK A.T. and E.P.; investigation and formal analysis of final compounds F.J.A.-T., G.R., A.F., P.M.L.-N. and L.C.L.-C.; investigation and formal analysis of biological assays D.G.-P., G.P.-M., C.B.-N., A.T. and E.P.; Supervision, L.C.L.-C., M.P.C.-J. and E.P.; funding acquisition, project administration and resources L.C.L.-C. and M.P.C.-J. All authors have read and agreed to the published version of the manuscript.

Funding: This research was funded by Convocatoria 2019 Proyectos de I + D + i - RTI Tipo B “Ministerio de Ciencia e Innovación" grant number PID2019-109294RB-I00, University of Granada, Cei-BioticProject grant number CEI2013-MP-1, the Instituto de Salud Carlos III Subdirección General de Redes y Centros de Investigación Cooperativa-Red de Investigación Cooperativa en Enfermedades Tropicales (RICET: RD16/0027/0014), the Plan Nacional (SAF PID2019-109623RB-I002016-79957-R) and the Junta de Andalucía (BIO-199).

Institutional Review Board Statement: The supply and use of red blood cells was evaluated by the Coordinating Committee on Ethics in Biomedical Research in Andalusia and approved by the Biobank of the Health System of the "Consejeria de Salud" of the Andalusian Government, (approval number 32170028PV01, on 16 February 2017).

Informed Consent Statement: Not applicable.

Data Availability Statement: Not applicable.

Conflicts of Interest: The authors declare no conflict of interest.

\section{References}

1. World Health Organization. World Malaria Report 2020: 20 Years of Global Progress and Challenges; Licence: CC BY-NC-SA 3.0 IGO; World Health Organization: Geneva, Switzerland, 2020.

2. Peyrottes, S.; Caldarelli, S.; Wein, S.; Périgaud, C.; Pellet, A.; Vial, H. Choline Analogues in Malaria Chemotherapy. Curr. Pharm. Des. 2012, 18, 3454. [CrossRef] [PubMed] 
3. Martinez-Peinado, N.; Lorente-Macías, A.; García-Salguero, A.; Cortes-Serra, N.; Fenollar-Collado, A.; Ros-Lucas, A.; Gascon, J.; Pinazo, M.J.; Molina, I.J.; Unciti-Broceta, A.; et al. Novel Purine Chemotypes with Activity against Plasmodium falciparum and Trypanosoma cruzi. Pharmaceuticals 2021, 14, 638. [CrossRef]

4. Jiang, X.; Yuan, Y.; Huang, J.; Zhang, S.; Luo, S.; Wang, N.; Pu, D.; Zhao, N.; Tang, Q.; Hirata, K.; et al. Structural Basis for Blocking Sugar Uptake into the Malaria Parasite Plasmodium falciparum. Cell 2020, 183, 258. [CrossRef]

5. Brancucci, N.M.; Gerdt, J.P.; Wang, C.; De Niz, M.; Philip, N.; Adapa, S.R.; Zhang, M.; Hitz, E.; Niederwieser, I.; Boltryk, S.D.; et al. Lysophosphatidylcholine Regulates Sexual Stage Differentiation in the Human Malaria Parasite Plasmodium falciparum. Cell 2017, 171, 1532. [CrossRef]

6. Torretta, A.; Lopez-Cara, L.C.; Parisini, E. Crystal Structure of the Apo and the ADP-Bound Form of Choline Kinase from Plasmodium falciparum. Crystals 2020, 10, 613. [CrossRef]

7. Serrán-Aguilera, L.; Denton, H.; Belén Rubio-Ruiz, B.; Borja López-Gutiérrez, B.; Entrena, A.; Izquierdo, L.; Smith, T.K.; Conejo-García, A.; Hurtado-Guerrero, R. Plasmodium falciparum Choline Kinase Inhibition Leads to a Major Decrease in Phosphatidylethanolamine Causing Parasite Death. Sci. Rep. 2016, 6, 1. [CrossRef] [PubMed]

8. Schiafino-Ortega, S.; Baglioni, E.; Pérez-Moreno, G.; Marco, P.R.; Marco, C.; González-Pacanowska, D.; Ruiz-Pérez, L.M.; CarrascoJiménez, M.P.; López-Cara, L.C. 1,2-Diphenoxiethane salts as potent antiplasmodial agents. Bioorg. Med. Chem. Lett. 2018, $28,2485$. [CrossRef] [PubMed]

9. Pérez-Moreno, G.; Cantizani, J.; Sánchez-Carrasco, P.; Ruiz-Pérez, L.M.; Martín, J.; El Aouad, N.; González-Pacanowsk, D. Discovery of new compounds active against Plasmodium falciparum by high throughput screening of microbial natural products. PLOS ONE 2016, 11, e0145812.

10. Rubio-Ruiz, B.; Castillo-Acosta, V.M.; Perez-Moreno, G.; Espinosa, A.; Gonzalez-Pacanowska, D.; Ruiz-Perez, L.M.; Entrena, A.; Conejo-García, A. In vitro antiplasmodial and cytotoxic activities of asymmetrical pyridinium derivatives. Eur. J. Med. Chem. 2014, 85, 289. [CrossRef]

11. Serrán Aguilera, L.; Mariotto, E.; Rubbini, G.; Castro Navas, F.F.; Marco, C.; Carrasco-Jiménez, M.P.; Ballarotto, M.; Macchiarulo, A.; Hurtado-Guerrero, R.; Viola, G.; et al. Synthesis, Biological evaluation, in silico modeling and Crystallisation of novel small monocationic molecules with potent antiproliferative activity by dual mechanism. Eur. J. Med. Chem. 2020, 207, 112797. [CrossRef] [PubMed]

12. Sahun-Roncero, M.; Rubio-Ruiz, B.; Saladino, G.; Conejo-Garcia, A.; Espinosa, A.; Velazquez-Campoy, A.; Gervasio, F.L.; Entrena, A.; Hurtado-Guerrero, R. The Mechanism of Allosteric Coupling in Choline Kinase1 Revealed by the Action of a Rationally Designed Inhibitor. Angew. Chem. Int. Ed. 2013, 52, 4582. [CrossRef] [PubMed]

13. Sahún-Roncero, M.; Rubio-Ruiz, B.; Conejo-Garcia, A.; Velázquez-Campoy, A.; Entrena, A.; Hurtado-Guerrero, R. Determination of Potential Scaffolds for Human Choline Kinase $\alpha 1$ by Chemical Deconvolution Studies. Chem. Bio. Chem. 2013, $14,1291$. [CrossRef] [PubMed]

14. Déchamps, S.; Wengelnik, K.; Vial, H.J. Glycerophospholipid acquisition in Plasmodium-A puzzling assembly of biosynthetic pathways. Int. J. Parasitol. 2010, 40, 1347. [CrossRef] [PubMed]

15. Mamoun, C.B.; Prigge, S.T.; Vial, H. Targeting the lipid metabolic pathways for the treatment of malaria. Drug Dev. Res. 2010, 71, 44. [CrossRef]

16. Mulaw Belete, T. Recent Progress in the Development of New Antimalarial Drugs with Novel Targets. Drug Des. Devel. Ther. 2020, 14, 3875. [CrossRef] [PubMed]

17. Romagnoli, R.; Prencipe, F.; Oliva, P.; Baraldi, S.; Baraldi, P.G.; Schiaffino Ortega, S.; Chayah, M.; Kimatrai Salvador, M.; Lopez-Cara, L.C. Design, Synthesis, and Biological Evaluation of 6-Substituted Thieno[3,2-d]pyrimidine Analogues as Dual Epidermal Growth Factor Receptor Kinase and Microtubule Inhibitors. J. Med. Chem. 2019, 62, 1274. [CrossRef]

18. Romagnoli, R.; Baraldi, P.G.; Carrion, M.D.; Cara, C.L.; Preti, D.; Fruttarolo, F.; Pavani, M.G.; Tabrizi, M.A.; Tolomeo, M.; Grimaudo, S.; et al. Synthesis and Biological Evaluation of 2- and 3-Aminobenzo[b]thiophene Derivatives as Antimitotic Agents and Inhibitors of Tubulin Polymerization. J. Med. Chem. 2007, 50, 2273-2277. [CrossRef] [PubMed]

19. Lima, L.M.; Barreiro, E.J. Bioisosterism: A useful strategy for molecular modification and drug design. Curr. Med. Chem. 2005, 12, 23. [CrossRef]

20. Chen, Y.; Yang, L.; Qiao, H.; Cheng, Z.; Xie, J.; Zhou, W.; Huang, X.; Jiang, Y.; Yu, B.; Zhao, W. Discovery of new thieno[3,2d]pyrimidine derivatives targeting EGFR(L858R/T790M) NSCLCs by the conformation constrained strategy. Eur. J. Med. Chem. 2020, 199, 112388. [CrossRef]

21. Picado, A.; Chaikuad, A.; Wells, C.I.; Shrestha, S.; Zuercher, W.J.; Pickett, J.E.; Kwarcinski, F.E.; Sinha, P.; de Silva, C.S.; Zutshi, R.; et al. A Chemical Probe for Dark Kinase STK17B Derives Its Potency and High Selectivity through a Unique P-Loop Conformation. Med. Chem. 2020, 63, 14626. [CrossRef]

22. Dimov, S.; Mavrova, A.T.; Yancheva, D.; Nikolova, B.; Tsoneva, I. Thieno[2,3-d]pyrimidin-4(3H)-one Derivatives of Benzimidazole as Potential Anti-Breast Cancer (MDA-MB-231, MCF-7) Agents. Anti Cancer Agents Med. Chem. 2021, 21, 1441. [CrossRef] [PubMed]

23. Faraji, A.; Bakhshaiesh, T.O.; Hasanvand, Z.; Motahari, R.; Nazeri, E.; Boshagh, M.A.; Firoozpour, L.; Mehrabi, H.; Khalaj, A.; Esmaeili, R.; et al. Design, synthesis and evaluation of novel thienopyrimidine-based agents bearing diaryl urea functionality as potential inhibitors of angiogenesis. Eur. J. Med. Chem. 2021, 209, 112942. [CrossRef] 
24. Yamada, S.; Flesch, K.N.; Murakami, K.; Itami, K. Rapid Access to Kinase Inhibitor Pharmacophores by Regioselective C-H Arylation of Thieno[2,3-d]pyrimidine. Org. Lett. 2020, 22, 1547. [CrossRef] [PubMed]

25. Rubbini, G.; Buades-Martín, A.B.; Kimatrai-Salvador, M.; Entrena, A.; Gallo-Mezo, M.Á.; Ríos-Marco, P.; Marco, C.; Mattiuzzo, E.; Bortolozzi, R.; Mariotto, E.; et al. Lead optimization-hit expansion of new asymmetrical pyridinium/quinolinium compounds as choline kinase $\alpha 1$ inhibitors. Future Med. Chem. 2018, 10, 1769. [CrossRef]

26. Schiaffino-Ortega, S.; Baglioni, E.; Mariotto, E.; Bortolozzi, R.; Serrán-Aguilera, L.; Ríos-Marco, P.; Carrasco-Jimenez, M.P.; Gallo, M.A.; Hurtado-Guerrero, R.; Marco, C.; et al. Design, synthesis, crystallization and biological evaluation of new symmetrical biscationic compounds as selective inhibitors of human Choline Kinase $\alpha 1$ (ChoK_1). Sci. Rep. 2016, 6, 23793. [CrossRef] [PubMed]

27. Schiaffino-Ortega, S.; Lopez-Cara, L.C.; Rios-Marco, P.; Carrasco-Jimenez, M.P.; Gallo, M.A.; Espinosa, A.; Marco, C.; Entrena, A. New non-symmetrical choline kinase inhibitors. Bioorg. Med. Chem. 2013, 21, 7146. [CrossRef] [PubMed]

28. Pravin, K.; Yarlagadda, B.; Kumar, V.; Weihe, Z.; Peng-Cheng, L. Imidazole-Containing Inhibitors of Alk2 Kinase. Patent WO2018232094, 15 June 2017.

29. Castro-Navas, F.F.; Schiaffino-Ortega, S.; Carrasco-Jimenez, M.P.; Rios Marco, P.; Marco, C.; Espinosa, A.; Gallo, M.A.; Mariotto, E.; Basso, G.; Viola, G.; et al. New more polar symmetrical bipyridinic compounds: New strategy for the inhibition of choline kinase alpha 1. Future Med. Chem. 2015, 7, 417-436. [CrossRef] [PubMed] 